\title{
Regional impacts of iron-light colimitation in a global biogeochemical model
}

\author{
E. D. Galbraith ${ }^{1, *}$, A. Gnanadesikan ${ }^{2}$, J. P. Dunne ${ }^{2}$, and M. R. Hiscock ${ }^{1}$ \\ ${ }^{1}$ AOS Program, Princeton University, Princeton, NJ 08544, USA \\ ${ }^{2}$ NOAA Geophysical Fluid Dynamics Laboratory, Princeton, NJ 08542, USA \\ *now at: Department of Earth and Planetary Science, McGill University, Montreal, QC, Canada
}

Received: 10 June 2009 - Published in Biogeosciences Discuss.: 27 July 2009

Revised: 18 February 2010 - Accepted: 3 March 2010 - Published: 18 March 2010

\begin{abstract}
Laboratory and field studies have revealed that iron has multiple roles in phytoplankton physiology, with particular importance for light-harvesting cellular machinery. However, although iron-limitation is explicitly included in numerous biogeochemical/ecosystem models, its implementation varies, and its effect on the efficiency of light harvesting is often ignored. Given the complexity of the ocean environment, it is difficult to predict the consequences of applying different iron limitation schemes. Here we explore the interaction of iron and nutrient cycles in an ocean general circulation model using a new, streamlined model of ocean biogeochemistry. Building on previously published parameterizations of photoadaptation and export production, the Biogeochemistry with Light Iron Nutrients and Gasses (BLING) model is constructed with only four explicit tracers but including macronutrient and micronutrient limitation, light limitation, and an implicit treatment of community structure. The structural simplicity of this computationallyinexpensive model allows us to clearly isolate the global effect that iron availability has on maximum light-saturated photosynthesis rates vs. the effect iron has on photosynthetic efficiency. We find that the effect on light-saturated photosynthesis rates is dominant, negating the importance of photosynthetic efficiency in most regions, especially the cold waters of the Southern Ocean. The primary exceptions to this occur in iron-rich regions of the Northern Hemisphere, where high light-saturated photosynthesis rates allow photosynthetic efficiency to play a more important role. In other words, the ability to efficiently harvest photons has little effect in regions where light-saturated growth rates are low. Additionally, we speculate that the phytoplankton cells dom-
\end{abstract}

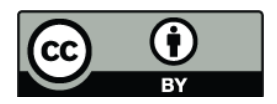

Correspondence to: E. D. Galbraith (eric.galbraith@mcgill.ca) inating iron-limited regions tend to have relatively high photosynthetic efficiency, due to reduced packaging effects. If this speculation is correct, it would imply that natural communities of iron-stressed phytoplankton may tend to harvest photons more efficiently than would be inferred from ironlimitation experiments with other phytoplankton. We suggest that iron limitation of photosynthetic efficiency has a relatively small impact on global biogeochemistry, though it is expected to impact the seasonal cycle of plankton as well as the vertical structure of primary production.

\section{Introduction}

In large surface regions of the open ocean, macronutrients remain in considerable abundance throughout the year, a puzzle that has engaged the interest of oceanographers for many decades. These High Nitrate Low Chlorophyll (HNLC) regions contrast with coastal environments in which the surface ecosystem handily strips out macronutrients, even where resupply rates are high. Although many factors have been implicated in the maintenance of HNLC regions, limitation by micronutrients - principally iron - clearly plays a central role.

Over the past decades, numerous experiments have shown that adding iron to macronutrient-rich regions of the ocean produces plankton blooms (see Boyd et al., 2007, for a review). On a physiological level, this appears to be largely due to the role of iron in the electron transport pathways that accomplish photosynthesis (Raven, 1990; Maldonado et al., 1999); cells that are replete in iron can build more photosynthetic reaction centers and utilize the light they intercept more efficiently (Greene et al., 1991; Strzepek and Harrison, 2004). Iron is also required for other cellular processes,

Published by Copernicus Publications on behalf of the European Geosciences Union. 
including the reduction of nitrate to ammonia (Raven, 1990; Price et al., 1991). Laboratory studies support this, reporting large decreases in growth rates under iron limitation (Price et al., 1991; Greene et al., 1991; Sunda and Huntsman, 1997; Timmermans et al., 2004). In addition, iron deficiency has been shown to significantly reduce the chlorophyll to carbon ratio, $\theta$, in almost all cases, due to the requirement for iron in chlorophyll biosynthesis (e.g. Greene et al., 1991; Sunda and Huntsman, 1997; Marchetti and Harrison, 2007).

While the impact of iron on photosynthesis is clearly important, the manner in which its effects should be implemented in numerical models is less clear. Recent representations of algal physiology in biogeochemical models have often relied on the photoadaptation scheme of Geider et al. (1997), used in numerous global models (e.g. Moore et al., 2002; Aumont and Bopp, 2006). This scheme is built around a common expression for the carbon-specific photosynthesis rate, $P^{\mathrm{C}}\left(\mathrm{s}^{-1}\right)$, as a function of irradiance, $I\left(\mathrm{~W} \mathrm{~m}^{-2}\right)$,

$P^{\mathrm{C}}=P_{\mathrm{m}}^{\mathrm{C}}\left\{1-\exp \left(-I / I_{\mathrm{k}}\right)\right\}$

where $P_{\mathrm{m}}^{\mathrm{C}}$ is a macronutrient-limited, temperaturedependent, light-saturated carbon-specific photosynthesis rate $\left(\mathrm{s}^{-1}\right)$ and $I_{\mathrm{k}}$ is a scaling term that determines the degree of light-limitation $\left(\mathrm{W} \mathrm{m}^{-2}\right)$. Note that photosynthesis is always light limited to some degree in this formulation (since $\left\{1-\exp \left(-I / I_{\mathrm{k}}\right)\right\}$ is always less than 1 ), and that for a given $I$, photosynthesis decreases with increasing $I_{\mathrm{k}}$. In the model of Geider et al. (1997), $\theta$ adapts to a phytoplankter's nutritional status, temperature, and light environment in a way that is consistent with laboratory experiments. This leads to a formulation for $I_{\mathrm{k}}$ as a function of $P_{\mathrm{m}}^{\mathrm{C}}, \theta$ and $\alpha^{\mathrm{chl}}$, the latter of which is the initial slope of the chlorophyll- $a$ specific photosynthesis-light response curve (units of $\mathrm{g} \mathrm{C} \mathrm{g} \mathrm{chl}^{-1} \mathrm{~W}^{-1} \mathrm{~m}^{2} \mathrm{~s}^{-1}$ ). This latter term governs how rapidly photosynthesis (relative to chlorophyll) increases with increasing light at low light levels, essentially a metric for the yield of usable photons harvested by each molecule of chorophyll under low light (Frenette et al., 1993). Substituting the Geider et al. (1997) formulation for $\theta$ in their equation for $I_{\mathrm{k}}$, we rearrange to obtain

$I_{\mathrm{k}}=\frac{P_{\mathrm{m}}^{\mathrm{C}}}{\alpha^{\mathrm{chl}} \theta_{\max }}+\frac{I_{\mathrm{mem}}}{2}$

where $\theta_{\max }$ is a scale factor for the ratio of chlorophyll

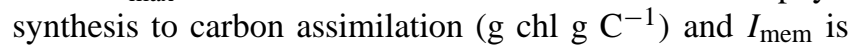
the irradiance to which the phytoplankton are accustomed. This equation captures the capacity of phytoplankton to adjust their photosynthetic machinery to their environment, in order to maximize photosynthesis rates while minimizing metabolic costs. In the Geider et al. (1997) formulation, $\theta_{\max }$ is not dependent on the nutrient supply to the plankton and simply equals the maximum chlorophyll-to-carbon ratio under extremely low light.

Within this widely-applied conceptual framework, the experimental evidence suggests that iron limitation could im- pact the growth of phytoplankton in three obvious ways. First, it could reduce the light-saturated growth rate $P_{\mathrm{m}}^{\mathrm{C}}$. This would represent the need for iron in proteins that mediate photosynthetic electron transport (Raven, 1990) and thereby determine the maximum yield of electrons for photosynthesis when light is abundant. Additionally, this term could account for the utility of iron for non-photosynthetic processes that are not explicitly resolved, such as nitrate reduction (Price et al., 1991). However, if $P_{\mathrm{m}}^{\mathrm{C}}$ is the only iron-dependent term, low iron will have the effect of making the plankton less light-limited, as they will need less light to match the other cellular functions (see the first term of Eq. 2). In other words, because Fe limitation reduces the maximum achievable photosynthetic rate, the utility of photons would decrease under $\mathrm{Fe}$ limitation, making light availability less important. This tendency would be counteracted by including iron dependencies in the two other obvious terms: $\alpha^{\text {chl }}$, so that photosynthetic efficiency decreases at low light under iron limitation, representing a reduction of the light harvesting elements; and $\theta_{\max }$, so that iron deficiency reduces chlorophyll synthesis and thereby causes $\theta_{\max }$ to decrease. Note that the second and third mechanisms are numerically linked in the photosynthesis formulation, through modification of $I_{\mathrm{k}}$ as the product $1 / \alpha^{\text {chl }} \theta_{\max }$. Allowing iron stress to modulate $\theta_{\max }$ differs from the Geider et al. (1997) treatment of macronutrients, in that iron stress reduces the synthesis of chlorophyll rather than by only reducing the demand for chlorophyll.

Applying iron dependencies to these three terms appears to broadly reflect the available measurements of photosynthetic parameters made during bottle incubations and mesoscale iron fertilization experiments. For example, in bottle incubations of natural samples from the Drake Passage, Hopkinson et al. (2007) reported that iron addition increased $\alpha^{\mathrm{chl}}, \theta$ and $P_{\mathrm{m}}^{\mathrm{B}}$ (the light-saturated chlorophyll-specific growth rate, equal to $P_{\mathrm{m}}^{\mathrm{C}} / \theta$ ). Marchetti et al. (2006a) also reported large increases in these three parameters, within an iron-fertilized patch of the subarctic Pacific during the SERIES experiment. Hiscock et al. (2008) presented observations from the SOFeX mesoscale iron enrichment experiment, showing an increase of $\alpha^{\text {chl }}$ by about $70 \%$ while quantum yield (effectively $\alpha^{\text {chl }} \theta$ ) increased by about twice as much, a factor of $\sim 2.5$; however, in their case the chlorophyll-specific photosynthesis rate $P_{\mathrm{m}}^{\mathrm{B}}$ remained relatively unchanged, indicating that any change in $P_{\mathrm{m}}^{\mathrm{C}}$ was approximately balanced by a corresponding change in $\theta$. Taken together, these results suggest that $P_{\mathrm{m}}^{\mathrm{C}}, \theta$ and $\alpha^{\text {chl }}$ can all change significantly as a function of Fe availability, although the magnitudes of the changes vary.

Recent versions of the Pelagic Interaction Scheme for Ecosystem Studies (PISCES), such as those used by $\mathrm{Au}-$ mont et al. (2008) and Tagliabue et al. (2009), include explicit iron dependencies for all three of these terms (L. Bopp, personal communication). Many other biogeochemical models include the effect of iron on $P_{\mathrm{m}}^{\mathrm{C}}$, but variation in $\theta$ and $\alpha^{\text {chl }}$ arise only indirectly, through changes in plankton composition (for models in which plankton functional types have 
different photosynthetic parameters), or not at all. Hence, it is useful to understand how including an iron dependency for each of these three photosynthetic parameters affects global biogeochemical cycling.

Introducing iron limitation alters the spatiotemporal distribution of nutrients, chlorophyll, and biomass in a way that will depend on the representation of grazing and export, the physical circulation regime, and the iron cycle itself. Understanding the dynamics of iron limitation at the global scale requires global models that consider both realistic physical transport and biology, and which can be deliberately manipulated in order to target isolated components of the problem. However, comprehensive state-of-the-art biogeochemical schemes used in earth system modeling typically include multiple functional groups with differing responses to iron and nutrient limitation, complex zooplankton dynamics (Aumont et al., 2003), interactions between nitrogen fixation and iron limitation (Moore and Doney, 2007), and interactions between the global oxygen cycle and nutrient limitation via denitrification (Schmittner et al., 2007), all of which introduce complicating feedbacks.

This paper presents a new model of global biogeochemical cycling (Biogeochemistry-with-Light-Iron-Nutrients-Gas or BLING) that includes a physiologically-based representation of light limitation and explicitly simulates limitation by both iron and a macronutrient, but parameterizes the net effects of community size structure, grazing, and export following the work of Dunne et al. (2005). Thus, it presents a reasonable framework in which to isolate the physiological effects of iron limitation, without nonlinear interactions between ecosystem components. The model is described in detail in Sect. 2. We then describe a series of experiments in which we isolate the impacts of iron dependencies on the global biogeochemical simulation, as described in Sect. 3 . Section 4 concludes the paper.

\section{Model description}

BLING was developed as an intermediary between complex, highly nonlinear biogeochemical-ecosystem models (e.g. Moore et al., 2004; Aumont and Bopp, 2006) and simple, idealized biogeochemical models that either ignore representation of ecosystem dynamics (e.g. Dutkiewicz et al., 2005; Doney et al., 2006) or that generate export production by forcing surface nutrients towards observations (e.g. Najjar and Orr, 1999; Gnanadesikan et al., 2002, 2004). Like these other coupled ocean-biogeochemical models, BLING is designed to be embedded within an ocean general circulation model, and produces a three-dimensional solution that changes with time according to the physical ocean environment.

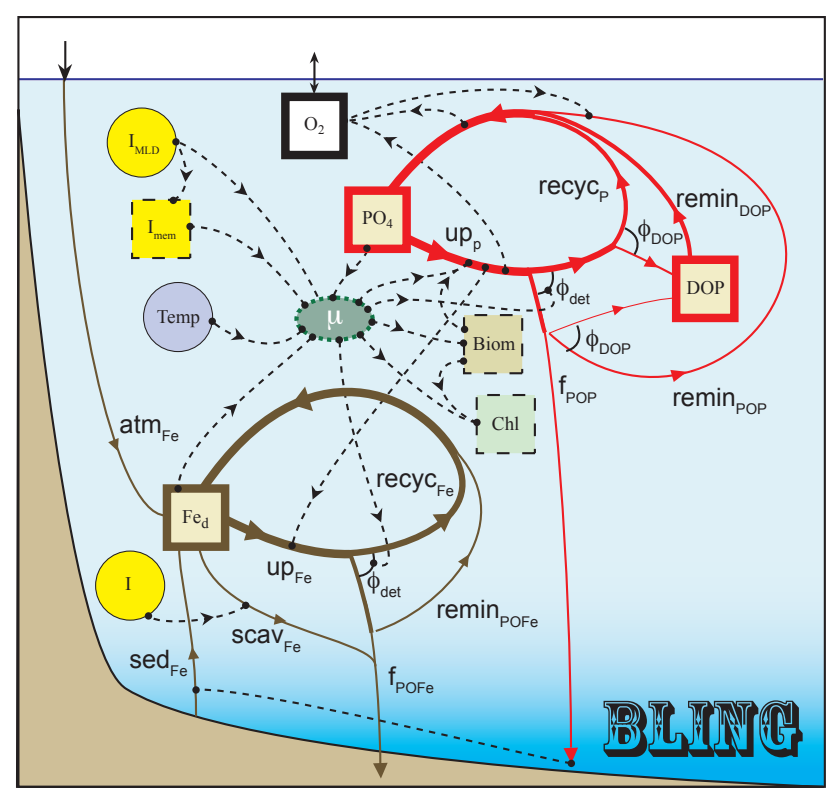

Fig. 1. Conceptual map of the Biogeochemistry with Light Iron Nutrients and Gas model. Prognostic tracers are shown as squares with solid outlines. Relevant environmental state variables are shown as circles. Diagnostic quantities are shown as squares with dashed outlines, where $\mathrm{Chl}$ is chlorophyll and Biom is biomass. The suite of plankton growth calculations are represented by the green oval. Solid lines show fluxes of prognostic quantities. Dashed lines (terminated by filled circles) indicate important interdependencies, with the arrow pointing toward the dependent variable.

BLING uses a relatively complex growth and export formulation, and is fully prognostic, in that the output depends only on in situ parameters provided by a physical circulation model, without restoring to observations. It is also "continuous", in that all equations are solved in all grid cells, with no arbitrary division between a shallow interval of export production and a remineralizing deep ocean; this allows ocean metabolism to arise purely from the physical forcing. Despite these features, the model only requires four explicit tracers (Fig. 1), which we call dissolved inorganic phosphorus $\left(\mathrm{PO}_{4}\right)$, dissolved organic phosphorus (DOP), dissolved iron $(\mathrm{Fe})$ and oxygen $\left(\mathrm{O}_{2}\right)$. It achieves this by treating the ecosystem implicitly, i.e. without any tracers that explicitly represent organisms. The core behavior of the model can therefore be thought of as an "NPZD" (nutrient, phytoplankton, zooplankton and detritus) model where the P, Z and D tracers are treated implicitly, so that computationally it is simply an "N" model. As a result, BLING is suitable for use in well-resolved physical models that include mixed-layer dynamics and a diurnal cycle, while remaining less complex than full ecosystem models. In addition, it requires only a marginal increase in computing cost beyond that required to run the physical ocean model alone. 
These simplifications provide multiple performance advantages, including more transparent behaviour, simpler code manipulation, and a reduction in the number of parameters that must be prescribed. However, they also present some obvious disadvantages compared to more complicated models. Foremost among these is the lack of explicit organic particles, so that only inorganic components are subject to advection and mixing by the ocean circulation, which could bias results in frontal regions at high resolution. In addition, with only four tracers, we cannot resolve the rich behaviour of the nitrogen cycle with its interactions with iron (Moore and Doney, 2007), phosphorus (Tyrell, 1999) and oxygen (Schmittner et al., 2007). Nor can we explicitly resolve changes in or differences between phytoplankton types (Bopp et al., 2005), variable stoichiometry in phytoplankton (Klausmeier et al., 2004), or zooplankton life histories. However, insofar as this model is able to simulate large-scale biogeochemical cycling with good skill, it suggests that additional complexity does not necessarily provide additional predictive ability, in terms of simulating the large-scale distributions of nutrients and chlorophyll.

Here we describe the version of the model used for the experiments in this paper, referred to as BLING.v0. Further information, updates, and model code are available on the website http://sites.google.com/site/blingmodel/.

\subsection{Growth rate formulation}

The growth rate of phytoplankton $(\mu)$ is calculated as a function of the ambient water characteristics: nutrient concentrations, light, and temperature. While the macronutrient- and temperature-dependent formulations used here are very typical of biogeochemical-ecosystem models, we use a novel scheme for representing iron limitation that does not rely exclusively on Liebig's law of the minimum (by which only the most limiting nutrient affects growth) but also incorporates nutrient-light co-limitation in a way that is broadly consistent with laboratory and field studies of phytoplankton.

The growth rate calculation begins by determining the light-saturated photosynthesis rate from the in situ conditions,

$P_{\mathrm{m}}^{\mathrm{C}}=P_{0}^{\mathrm{C}} \times \exp (k T) \times \min \left(\operatorname{Def}_{\mathrm{Fe}}, \frac{\mathrm{PO}_{4}}{K_{\mathrm{PO} 4}+\mathrm{PO}_{4}}\right)$

which depends on a specified maximum photosynthesis rate at temperature $T=0^{\circ} \mathrm{C}\left(P_{0}^{\mathrm{C}}\right)$, a temperature-dependent term with $k=0.063^{\circ} \mathrm{C}^{-1}$ following Eppley (1972), and a limitation by iron and phosphate following Liebig's law of the minimum. Phosphate limitation is given by the simple Monod relationship as shown, which depends only on the halfsaturation constant $K_{\mathrm{PO} 4}$, while Fe limitation is expressed by the term $\operatorname{Def}_{\mathrm{Fe}}$ as described below.

In calculating Def $\mathrm{Fe}_{\mathrm{Fe}}$ we represent the fact that, in contrast to nitrogen and carbon, $\mathrm{Fe}$ is taken up by phytoplankton in a highly variable ratio to phosphorus (e.g. Sunda and Huntsman, 1997; Marchetti et al., 2006b; Boyd et al., 2007). We calculate this uptake ratio directly from the ambient water chemistry as

$(\mathrm{Fe}: \mathrm{P})_{\text {uptake }}=(\mathrm{Fe}: \mathrm{P})_{0} \times \frac{\mathrm{Fe}}{K_{\mathrm{Fe}}+\mathrm{Fe}}$

where $\mathrm{Fe}$ is the dissolved iron concentration, $(\mathrm{Fe}: \mathrm{P})_{0}$ is a maximal uptake ratio and $K_{\mathrm{Fe}}$ defines the half-saturation constant for the uptake ratio. Although very simple, this formulation results in a correlation between $(\mathrm{Fe}: \mathrm{P})_{\text {uptake }}$ and dissolved $\mathrm{Fe}$ concentrations that approximates the response shown in laboratory studies such as that of Sunda and Huntsman (1997). Since, for balanced growth, the uptake ratio is equal to the cell quota, we can calculate iron limitation directly from $(\mathrm{Fe}: \mathrm{P})_{\text {uptake }}$,

$\operatorname{Def}_{\mathrm{Fe}}=\frac{(\mathrm{Fe}: \mathrm{P})_{\text {uptake }}}{K_{\mathrm{Fe}: \mathrm{P}}+(\mathrm{Fe}: \mathrm{P})_{\text {uptake }}} \times \frac{K_{\mathrm{Fe}: \mathrm{P}}+(\mathrm{Fe}: \mathrm{P})_{0}}{(\mathrm{Fe}: \mathrm{P})_{0}}$

where $K_{\mathrm{Fe}: \mathrm{P}}$ defines the half-saturation cellular Fe:P quota, i.e. the ratio at which the iron limitation term equals 0.5 . The second term in Eq. (5) normalizes the expression, so that at high concentrations of dissolved iron, Def $f_{\mathrm{Fe}}$ approaches 1. Functionally, the summed effect of Eqs. (4) and (5) on growth corresponds to a Michaelis-Menten curve with a halfsaturation constant $K^{\prime}=K_{\mathrm{Fe}} \cdot K_{\mathrm{Fe}: \mathrm{P}} /\left(K_{\mathrm{Fe}: \mathrm{P}}+(\mathrm{Fe}: \mathrm{P})_{0}\right)$, such that growth rates decrease more slowly than the uptake ratio as iron becomes more scarce. Treating uptake in this fashion allows the implicit cellular Fe:P to increase as Fe concentrations increase, but with diminishing physiological returns, consistent with the notion of "luxury" uptake (Sunda and Huntsman, 1997; Marchetti et al., 2009). Note that we do not alter the uptake ratio as a function of light availability.

Iron limitation can also be applied to two additional components of the general Geider et al. (1997) photosynthesis rate formulation, introduced in Eq. (2) above, as follows:

$\alpha^{\mathrm{chl}}=\alpha_{\min }^{\mathrm{chl}}+\left(\alpha_{\max }^{\mathrm{chl}}-\alpha_{\min }^{\mathrm{chl}}\right) \times \operatorname{Def}_{\mathrm{Fe}}$

$\theta_{\max }^{\mathrm{Fe}}=\theta_{\min }+\left(\theta_{\max }-\theta_{\min }\right) \times \operatorname{Def}_{\mathrm{Fe}}$

where $\theta_{\max }^{\mathrm{Fe}}$ modulates $\theta$ by replacing $\theta_{\max }$. Together, these exacerbate the tendency for light limitation under iron stress, representing co-limitation by iron and light. Note that we chose linear dependencies in order to minimize complexity, rather than based on first principles, and that both $\alpha^{\text {chl }}$ and $\theta_{\max }^{\mathrm{Fe}}$ are restricted to vary between prescribed maxima and minima; alternative formulations exist, such as that of Fasham et al. (2006). The overall, light-limited photosynthesis rate is then calculated by Eq. (1), in which $I$ is the in-situ irradiance, except within the mixed layer where the irradiance is vertically averaged in order to implicitly represent the turbulent transport of phytoplankton throughout the mixed layer. Note that the irradiance used for calculating $\theta$ and $I_{\mathrm{k}}\left(I_{\mathrm{mem}}\right)$ is smoothed over one day to represent a small 


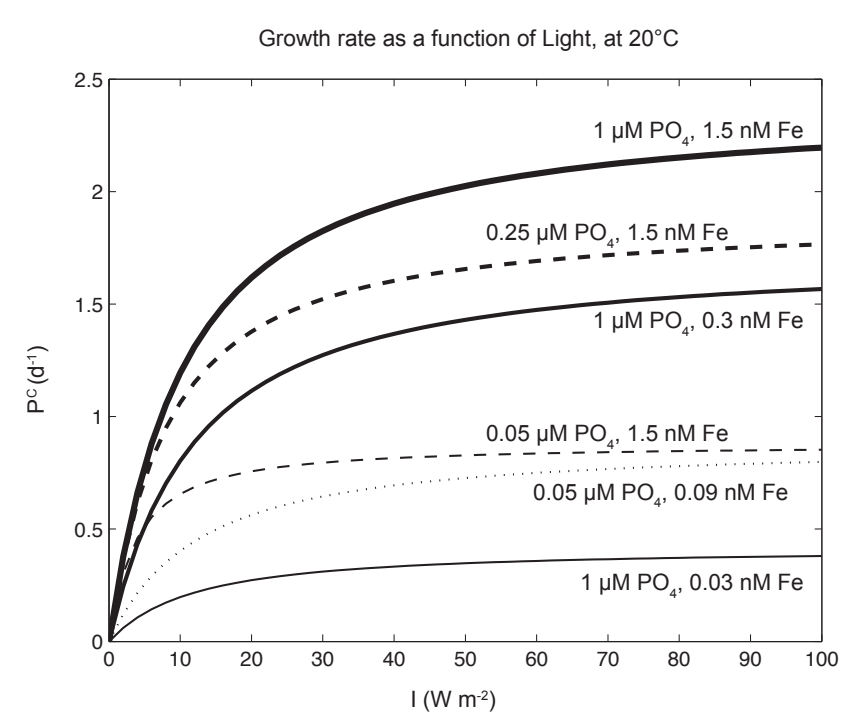

Fig. 2. Photosynthesis rate at $20^{\circ} \mathrm{C}$ as a function of light intensity $(I)$, for a variety of nutrient availabilities, with all three iron dependent terms. The heavy solid line represents $\mathrm{PO}_{4}$ and Fe replete conditions. Other solid lines show $\mathrm{PO}_{4}$ replete photosynthesis rates at two limiting Fe concentrations, while dashed lines show Fe replete photosynthesis rates at two limiting $\mathrm{PO}_{4}$ concentrations. The dotted line shows photosynthesis rates when both $\mathrm{PO}_{4}$ and $\mathrm{Fe}$ are limiting. Note that the approach to light-saturated photosynthesis rates is more gradual when iron is limiting, due to the reduction of photosynthetic efficiency.

lag as phytoplankton adapt to ambient light levels (Dusenberry et al., 2001), allowing use in physical models that include a diurnal cycle.

Even with this small number of equations, the resulting interdependence on iron, light, temperature, and macronutrient is significantly nonlinear. As illustrated in Fig. 2, the Geider (1997) formulation predicts that the total photosynthesis rate $P^{\mathrm{C}}$ increases as $I$ increases, but the response to $I$ saturates more quickly when $P_{\mathrm{m}}^{\mathrm{C}}$ is small (either because of nutrient limitation or low temperature), since fewer photons are required to achieve the slower light-saturated photosynthesis rates. This can be seen by inspection of Eq. (2), in which the first term, $P_{\mathrm{m}}^{\mathrm{C}} / \alpha^{\mathrm{chl}} \theta_{\mathrm{max}}^{\mathrm{Fe}}$, gives the dependence of light limitation on temperature and nutrient availability: when this term is large, more light is required to approach light-saturated rates. Equation (2) also reveals that the iron dependencies of $\alpha^{\text {chl }}$ and $\theta_{\max }^{\mathrm{Fe}}$ carry more weight when $P_{\mathrm{m}}^{\mathrm{C}}$ is large, and/or when the second term of Eq. (2), (I/2), is small. Thus, under low light, and at high temperatures, iron limitation has a larger impact on the degree of light limitation. Meanwhile, at high $\mathrm{PO}_{4}$ concentrations, Fe has a very large impact on $P_{\mathrm{m}}^{\mathrm{C}}$ through the Liebig limitation term, whereas when $\mathrm{PO}_{4}$ concentrations limit $P_{\mathrm{m}}^{\mathrm{C}}$, iron limitation mainly acts through its effect on $I_{\mathrm{k}}$.

Finally, combining our iron limitation scheme with the Geider et al. (1997) formulation, we can diagnose a chlorophyll to carbon ratio $\theta=\frac{\theta_{\max }^{\mathrm{Fe}}}{1+\alpha^{\mathrm{chl}} \theta_{\max }^{\mathrm{Fe}} I_{\mathrm{mem}} / 2 P_{\mathrm{m}}^{\mathrm{C}}}$

Increasing the iron concentration will thus affect $\theta$ via all three iron-dependent terms. First, the increase of $P_{\mathrm{m}}^{\mathrm{C}}$ will increase $\theta$, as plankton manufacture chlorophyll in an attempt to provide energy to achieve the higher light-saturated photosynthesis rate. Second, the increase of $\theta_{\max }^{\mathrm{Fe}}$ will cause $\theta$ to increase, with more impact at low light levels than at high light levels. Third, an increase of $\alpha^{\text {chl }}$ will tend to decrease $\theta$, particularly at high light (since a given amount of chlorophyll becomes more efficient at processing light). The net effect of iron addition on $\theta$, as well as growth rate, is therefore dependent on multiple environmental conditions.

The carbon-specific growth rate, $\mu$, is equal to the photosynthesis rate minus respiration. For simplicity, we follow Geider et al. (1997) in assuming that respiration is a fixed fraction of the growth rate, and is thus incorporated into $P^{\mathrm{C}}$ for the experiments described here, so that $\mu=P^{\mathrm{C}}$ or the remainder of the discussion. All calculations are made in terms of phosphorus, and are converted to carbon units assuming a constant $\mathrm{C}: \mathrm{P}$ of 106 and to oxygen units using an $\mathrm{O}_{2}: \mathrm{P}$ of 150 (Anderson, 1995).

\subsection{Mortality rate formulation}

The uptake of nutrients by phytoplankton depends on the carbon-specific growth rate, multiplied by the biomass of living phytoplankton. The biomass, in turn, evolves due to a small residual between total growth and total mortality rates. Many models keep track of these terms explicitly, allowing direct calculation of mortality, but incorporating additional computational expense. However, it is also possible to calculate the biomass associated with a particular growth rate implicitly, circumventing the need for explicit biomass tracers, if we apply a simple mortality law.

Following the global observational synthesis of Dunne et al. (2005) we assume a mortality law of the form

Growth $=\mu B=\lambda\left(B / P^{*}\right)^{a} B=$ Mortality

where $B$ is the biomass in mol $\mathrm{P} \mathrm{kg}^{-1}, \lambda$ is the temperaturedependent mortality rate (equivalent to the sum of all losses of living biomass through grazing, viral lysis, etc.), and $P^{*}$ is the pivotal phytoplankton concentration at which a size class becomes the dominant food source. The term $a$ represents a mortality exponent, as discussed by Dunne et al. (2005). If $a=1$, the formulation corresponds to classic logistic growth, in which the mortality rate is linearly proportional to population density. We assume that the temperature dependence of mortality is identical to that of growth such that $\lambda=\lambda_{0} e^{k T}$, where $\lambda_{0}$ is the biomass-specific mortality rate at $0^{\circ} \mathrm{C}$. The biomass $B_{x}$ associated with the growth rate of a particular class of phytoplankton $x$ is then $B_{x}=\left(\mu_{x} / \lambda\right)^{1 / a_{x}} \times P^{*}$ so that the uptake rate of $\mathrm{PO}_{4}$ is given as

$V_{\mathrm{PO} 4_{\mathrm{x}}}=\left(\mu_{x} / \lambda\right)^{1 / a_{x}} \times P^{*} \times \mu_{x}$ 

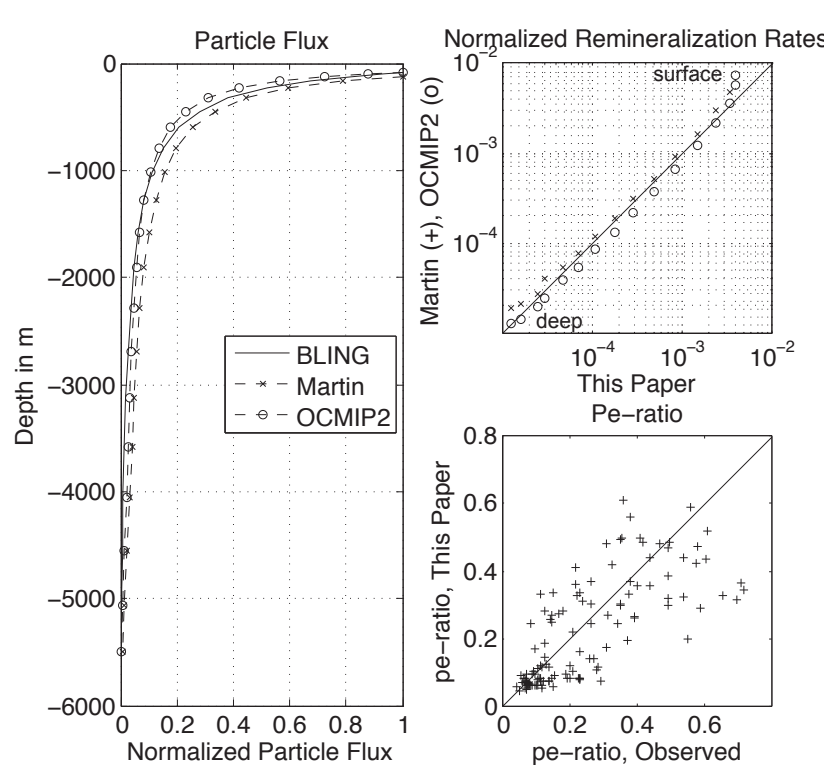

Fig. 3. Particle fluxes in the BLING-om1p7 model. (a) Profile of particle flux compared with Martin et al. (1987) and OCMIP2 particle flux curves. (b) Log of remineralization rate (\% production $/ \mathrm{m})$ compared with previous work. (c) Ratio of sinking particulate material to primary production using this formulation, compared with observations compiled by Dunne et al. (2005).

Following most ecosystem models, we conceptualize the phytoplankton as including two subpopulations: "large", which are consumed by mesozooplankton and are more likely to form sinking particles, and "small", which are consumed by microzooplankton and are more likely to decompose to dissolved and suspended organic matter. If we assume that small and large phytoplankton growth rates are the same under the same conditions (probably incorrect, but a useful simplifying assumption), $B_{x}=(\mu / \lambda)^{1 / a_{x}} \times P^{*}$. We follow Dunne et al. (2005) in using $a=1$ for small phytoplankton (corresponding to an assumption that the rapidly reproducing microzooplankton concentrations match small phytoplankton concentrations) and $a=1 / 3$ for large phytoplankton.

This formulation produces a cubic relationship between large and small plankton, consistent with the field data compilation of Agawin et al. (2000), and represents a fundamental building block both of our model and of the more complex TOPAZ biogeochemical model (Dunne et al., 2010), used in the GFDL Earth System Model. The total uptake is then

$V_{\mathrm{PO} 4}=\left((\mu / \lambda)^{3}+(\mu / \lambda)\right) \times \mu \times P^{*}$

Following Dunne et al. (2005) we use values of $\lambda_{0}=0.19$ day $^{-1}$ and $P^{*}=1.9 \mu \mathrm{mol} \mathrm{C} \mathrm{kg}^{-1}$.

This key relationship allows us to diagnose a number of useful properties. For example, the biomass is

$B=\left((\mu / \lambda)^{3}+(\mu / \lambda)\right) P^{*}=B_{\text {large }}+B_{\text {small }}$
Note that since the temperature dependence $e^{k T}$ appears in both the numerator and denominator of each term, the biomass itself is independent of temperature. From Eq. (10) the fraction of biomass associated with large phytoplankton frac $_{\mathrm{L}}$ is simply

$\operatorname{frac}_{\mathrm{L}}=\frac{B_{\text {large }}}{B_{\text {large }}+B_{\text {small }}}=\frac{(\mu / \lambda)^{2}}{1+(\mu / \lambda)^{2}}$

such that at $0^{\circ} \mathrm{C}$, if the growth rates exceed $\sim 0.19 \mathrm{day}^{-1}$, large phytoplankton will be in the majority, while at $28^{\circ} \mathrm{C}$ the growth rate must exceed 1.1 day $^{-1}$ for this to be true.

\subsection{Organic matter cycling}

Field observations show that nutrient elements are efficiently recycled within the mixed layer, with a relatively small fraction being exported as dissolved or particulate organic material (Dugdale and Goering, 1967). In order to model a realistic relationship between gross primary production and export production, we must therefore represent the division of nutrient uptake between recycling and export. Once again we follow the work of Dunne et al. (2005) who examined 119 globally distributed sites at which the ratio between particulate export and primary production (the pe-ratio) could be estimated from observations. They developed a formulation that linked the pe-ratio to water column remineralization, in terms of the production of detritus and ballasting material associated with coccolithophorids and diatoms. As we do not explicitly represent sinking detritus, we reanalyze the Dunne et al. (2005) dataset in terms of a simpler model of particle sinking and remineralization.

As was recently noted by Kriest and Oschlies (2008) the classic "Martin curve" profile for remineralization is consistent with a sinking speed that increases linearly with depth and a remineralization rate that is constant. We chose a sinking speed of $16 \mathrm{~m} /$ day over the top $80 \mathrm{~m}$, increasing linearly below that depth at a rate of $0.05(\mathrm{~m} / \mathrm{day}) / \mathrm{m}$ and an oxygen-dependent remineralization rate with a maximum of $\gamma_{\text {POP }}$ of $0.12 \mathrm{day}^{-1}$. Figure $3 \mathrm{a}$ shows the resulting profile of particle flux, which lies between the classic Martin curve of $F=F(z=100 \mathrm{~m}) \times(z / 100)^{-0.868}$ and the function $F=F(z=75 \mathrm{~m}) \times(z / 75)^{-0.9}$ used for the OCMIP2 simulations (see for example Gnanadesikan et al., 2002, 2004). The remineralization rates (\% primary production $/ \mathrm{m}$ ), shown in Fig. $3 b$, are similar to the previous parameterizations over most of the water column.

Following Dunne et al. (2005) we link large and small phytoplankton to a remineralization scheme to derive a particle export ratio. We calculate values of $\phi_{\mathrm{L}}$ and $\phi_{\mathrm{S}}$, the detrital production fractions associated with large and small phytoplankton respectively, to match the observational compilation in Dunne et al. (2005). The resulting values of $\phi_{\mathrm{L}}=1.0$ and $\phi_{S}=0.18$ provide a fit that explains more than $60 \%$ of the variance in the observations, as illustrated in Fig. 3c, comparable to the fits found in Dunne et al. (2005). The detritus 
production tends to be less than half the total uptake, and can be as little as one tenth in warm, low-productivity waters. The non-detritus remainder is then subdivided, such that a constant fraction $\phi_{\text {DOP }}$ is converted to dissolved organic phosphorus, with the residual being instantaneously recycled to inorganic $\mathrm{PO}_{4}$ to represent the microbial loop (Fig. 1). The magnitude of gross uptake (primary production) is strongly dependent on this subdivision, but it has little effect on export production. The remineralization of sinking detritus also produces both dissolved inorganic and dissolved organic phosphorus, in the same ratio $\phi_{\text {DOP. }}$. Dissolved organic phosphorus remineralizes according to the first order rate constant $\gamma_{\text {DOP. }}$

\subsection{Iron cycling}

The iron cycle is inherently more complex than the phosphate cycle, primarily because dissolved iron concentrations are more intensely modified by interactions with particles than are dissolved phosphate concentrations (Parekh et al., 2005). In an oxygenated environment, iron (II) and (III) form colloids that are readily scavenged by organic and mineral sinking particles, removing them from the water column (Wu et al., 2001). On the other hand, iron can also be chelated by dissolved organic ligands, whose concentrations can greatly exceed that of the iron itself, preventing the adsorption of iron to particles (Rue and Bruland, 1995). Meanwhile, the uptake of chelated iron by plankton (Tortell et al., 1999) and the photochemical breakdown of ligands (Barbeau et al., 2001) can result in relatively short lifetimes for iron in the surface ocean (Weber et al., 2005; Tagliabue and Arrigo, 2006). As a result of its high reactivity and rapid removal from the ocean, the lifetime of iron in the ocean is much shorter than that of phosphate or nitrate, resulting in a tight coupling of the iron distribution to its source regions (Johnson et al., 1997). These sources include runoff (Hutchins et al., 1998), mineral dust (Mahowald et al., 2005; Ginoux et al., 2004) and sediments (Lam et al., 2006; Moore and Braucher, 2008).

Given that the understanding of multiple forms of iron remains rudimentary, we follow previous workers (e.g. Moore et al., 2004; Parekh et al., 2005; Aumont and Bopp, 2006) in defining a single pool of "dissolved" iron. Iron is supplied to the ocean surface layer according to a prescribed climatological aeolian dust source (Ginoux et al., 2004) which totals

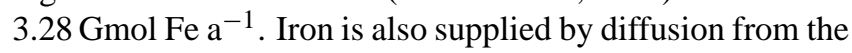
seafloor, representing the release of iron from organic and mineral phases in the sediment, as the product of the prescribed constant $\mathrm{Fe}: \mathrm{P}_{\text {sed }}$ and the flux of organic phosphorus to the seafloor, following Moore and Braucher (2008). Thus, the sedimentary iron efflux varies with global export production, but is on the order of $8 \mathrm{Gmol} \mathrm{Fe} \mathrm{a}^{-1}$ in the simulations shown here.

We also include an implicit ligand, with a globally uniform concentration of $1 \mathrm{nM}$ following Parekh et al. (2005).
We allow the ligand stability constant $K_{\mathrm{FeL}}$ to decrease from $K_{\mathrm{FeL}}^{\max }$ toward $K_{\mathrm{FeL}}^{\min }$ in surface waters, which are diagnosed as a function of light intensity Iusing a Holling type 3 function, inspired by the observed photodissociation of iron-ligand complexes in surface waters (Barbeau et al., 2001, 2003):

$$
\begin{aligned}
K_{\mathrm{FeL}}= & K_{\mathrm{FeL}}^{\max }-\left(K_{\mathrm{FeL}}^{\max }-K_{\mathrm{FeL}}^{\min }\right) \cdot \frac{I^{2}}{I_{\mathrm{FeL}}^{2}+I^{2}} \\
& \cdot \max \left(0, \min \left(1, \frac{\mathrm{Fe}-\mathrm{Fe}_{\mathrm{min}}}{\mathrm{Fe}} \cdot b\right)\right)
\end{aligned}
$$

where the coefficient $b$ (equal to 1.2 ) is such that $K_{\mathrm{FeL}}$ approaches $K_{\mathrm{FeL}}^{\mathrm{max}}$. Since ligands and their reaction to light are not explicitly modeled, the light sensitivity parameter, $I_{\mathrm{FeL}}$, is set to a low value to maintain low values of $K_{\mathrm{FeL}}$ throughout the euphotic zone. The latter term in Eq. (14) reduces photodissociation when iron concentrations $\mathrm{Fe}$ approach $\mathrm{Fe}_{\min }$, an effect similar to the formation of siderophores (strong ligands) by microbes under iron stress (Trick et al., 1983; Granger and Price, 1999). This results in a more rapid removal of iron from the surface ocean when iron concentrations are significantly in excess of $\mathrm{Fe}_{\min }$, improving the simulation, a result that Moore and Braucher (2008) achieve instead by increasing the scavenging rate constant by roughly a factor of 6 in the upper ocean. We emphasize that this is an ad hoc approach, as currently required by the incomplete understanding of environmental controls on the speciation of iron, and hope that it will be improved in future generations of the model as more information becomes available.

Free dissolved iron, i.e. not bound to the ligand, is scavenged by two mechanisms in oxic waters. The first, after Parekh et al. (2005), calculates a first-order scavenging rate constant as a function of the sinking flux of organic matter:

$\mathrm{Fe}_{\mathrm{ads}}^{\mathrm{org}}=k_{\mathrm{Fe}}^{\mathrm{org}} \cdot\left(\frac{f_{\mathrm{POC}}}{w_{\text {sink }}}\right)^{0.58} \cdot \mathrm{Fe}^{\prime}$

where the exponent of 0.58 is taken from the empirical study of Honeyman et al. (1988). Alone, this would ignore the unresolved effect of lithogenic material as a scavenging agent, as well as the inorganic formation of colloids. Therefore we include a second type of scavenging to represent these processes:

$\mathrm{Fe}_{\text {ads }}^{\text {inorg }}=k_{\mathrm{Fe}}^{\text {inorg }} \cdot \mathrm{Fe}^{\prime 1.5}$

Because the underlying processes are poorly understood, we use a globally uniform rate constant. The fact that colloid formation would tend to be somewhat more rapid where iron concentrations are high leads us to increase the order of the iron concentration dependence to 1.5 , intermediate between a linear and a quadratic dependence. In practical terms, the latter acts to prevent dissolved iron concentrations from growing very large in regions with high inputs, such as the beneath the Saharan dust plume, while still allowing for enhanced 
Table 1. Parameters used in BLING for the experiments shown here. Reference values are given, where appropriate, in italics. Otherwise, the initial guess is shown.

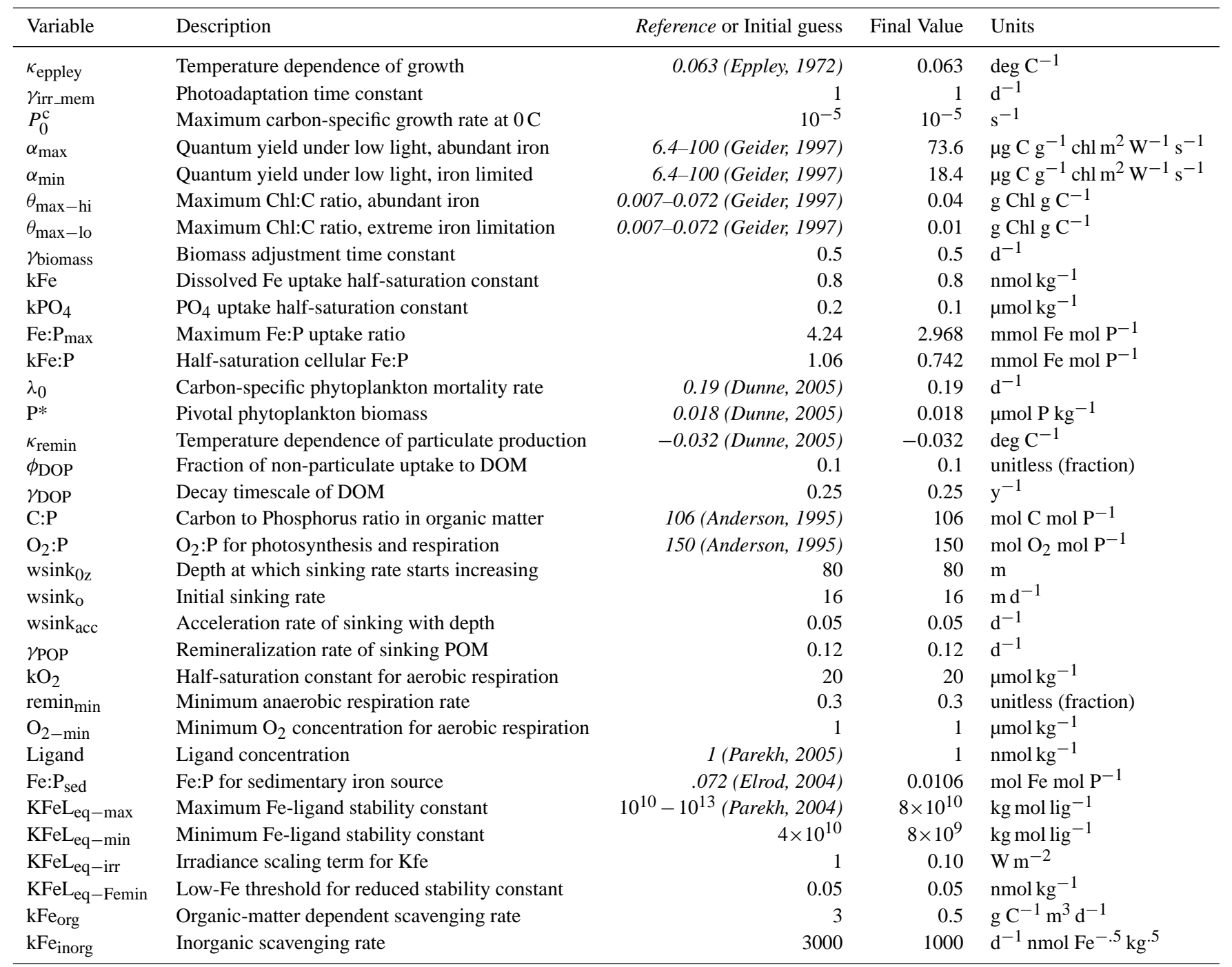

concentrations in these regions. Again, improving these parameterizations is a clear target for future work.

It is assumed that scavenged iron is released to the water column as it sinks; thus, adsorbed iron is returned to the dissolved pool following the same instantaneous sinking and remineralization routine applied to the particulate organic iron produced by phytoplankton uptake. Particulate iron that sinks out of the bottom ocean layer is permanently removed from the ocean, as long as oxygen concentrations are greater than the anoxic threshold. Otherwise, the sedimented iron is instantaneously returned to the bottom layer.

\subsection{Parameter choices}

Parameter values (shown in Table 1) were initially selected based on a survey of the available literature and/or first principles, and adjusted when necessary in order to obtain a solution that compares reasonably well with observations. Note that the parameter ranges for $\alpha^{\text {chl }}$ and $\theta_{\max }^{\mathrm{Fe}}$ were set to provide identical responses to $\operatorname{Def}_{\mathrm{Fe}}$, rather than as optimal fits to the data. The simulation was compared to the World Ocean Atlas 2001 and 2005, the dissolved iron compilation of Moore and Braucher (2008), the A16 section of Measures et al. (2008), and SeaWiFS satellite observations of chlorophyll (Level 3 SeaWiFS chlorophyll- $a$ concentration data, OC4, reprocessing v5.2, for September 
Table 2. Correlation, regression (italicized) coefficients and RMS errors (in bold) for the output of the model suite used here.

\begin{tabular}{|c|c|c|c|c|c|c|c|c|}
\hline $\begin{array}{l}\text { Corr, Reg } \\
\text { Err }\end{array}$ & $\begin{array}{c}\text { All } \\
\text { Mean }\end{array}$ & $\operatorname{Var} \alpha$ & $\operatorname{Var} \theta$ & $\begin{array}{l}\operatorname{Var} \alpha+ \\
\operatorname{Var} \theta\end{array}$ & $\begin{array}{c}\text { Var } \\
\text { Liebig }\end{array}$ & $\begin{array}{c}\text { Var } \theta+ \\
\text { Liebig }\end{array}$ & $\begin{array}{l}\text { Var } \alpha+ \\
\text { Liebig }\end{array}$ & $\begin{array}{l}\text { All } \\
\text { Var }\end{array}$ \\
\hline Annual & 0.73 & 0.84 & 0.84 & 0.90 & 0.93 & 0.93 & 0.93 & 0.93 \\
\hline Mean & 0.49 & 0.64 & 0.64 & 0.75 & 0.88 & 0.88 & 0.88 & 0.89 \\
\hline $\mathrm{PO}_{4}$ & 0.43 & 0.34 & 0.34 & 0.27 & 0.20 & 0.20 & 0.20 & 0.20 \\
\hline \multirow{3}{*}{$\begin{array}{l}\text { Annually } \\
\text { varying } \\
\mathrm{PO}_{4}\end{array}$} & 0.70 & 0.81 & 0.81 & 0.88 & 0.92 & 0.91 & 0.91 & 0.91 \\
\hline & 0.50 & 0.64 & 0.64 & 0.75 & 0.86 & 0.87 & 0.87 & 0.87 \\
\hline & 0.45 & 0.37 & 0.37 & 0.29 & 0.23 & 0.22 & 0.22 & 0.23 \\
\hline \multirow{3}{*}{$\begin{array}{l}\text { Minimum } \\
\mathrm{PO}_{4}\end{array}$} & 0.47 & 0.70 & 0.70 & 0.81 & 0.86 & 0.85 & 0.85 & 0.84 \\
\hline & 0.26 & 0.48 & 0.48 & 0.67 & 0.92 & 0.92 & 0.92 & 0.93 \\
\hline & 0.48 & 0.38 & 0.38 & 0.28 & 0.18 & 0.19 & 0.19 & 0.19 \\
\hline Annual & 0.70 & 0.66 & 0.73 & 0.68 & 0.74 & 0.74 & 0.66 & 0.62 \\
\hline $\begin{array}{l}\text { Mean } \\
\log (\mathrm{Chl})\end{array}$ & 0.87 & 0.84 & 0.87 & 0.81 & 0.76 & 0.76 & 0.70 & 0.70 \\
\hline $\begin{array}{l}\text { Zonal } \\
\text { Mean PP } \\
\text { (vs. Carr) }\end{array}$ & 0.66 & 0.72 & 0.72 & 0.78 & 0.84 & 0.83 & 0.83 & 0.82 \\
\hline $\begin{array}{l}\text { Zonal } \\
\text { Mean PE } \\
\text { (vs. Carr) }\end{array}$ & 0.50 & 0.59 & 0.59 & 0.65 & 0.70 & 0.68 & 0.68 & 0.65 \\
\hline
\end{tabular}

1997-December 2007, downloaded from http://oceancolor. gsfc.nasa.gov/).

\subsection{Physical model}

The BLING model was embedded in the ocean component of the GFDL coarse-resolution global coupled climate model, CM2Mc (Galbraith et al., 2010). This uses the MOM4p1 code with pressure as the vertical coordinate, a free surface, "real" freshwater fluxes and a dynamic-thermodynamic sea ice module. The nominal resolution of this model, OM1p7, is 3 degrees in the east-west direction, with resolution in the north-south direction varying from 3 degrees in mid-latitudes to 2/3 degree near the equator. Enhanced resolution is also applied at the latitudes of the Drake Passage as well as at the symmetrically equivalent latitudes of the Northern Hemisphere. A tripolar grid is applied to the Arctic, as in GFDL's CM2.0 and CM2.1 models (Griffies et al., 2005). The vertical resolution is 28 levels, ranging from $10 \mathrm{~m}$ resolution at the surface to $506 \mathrm{~m}$ in the lowermost layer. Tracer advection uses the Sweby MDFL scheme. The surface forcing is a repeated climatological year derived from the Coordinated Ocean Reference Experiment (Griffies et al., 2009), which also supplies shortwave irradiance to the ocean (there is no diurnal cycle). Surface salinities are restored to observations with a time constant of 10 days over the top layer.

Light is absorbed by water and a smoothly-varying, satellite-derived climatological chlorophyll field following the Manizza et al. (2005) algorithm, held constant for all experiments. Doing this means that changes in the representation of iron limitation will not change the physical circulation and so any resulting changes in biology can be directly attributed to changes in biogeochemical cycling - simplifying interpretation of the changes we see here.

Subgridscale parameterizations for mixing are similar to those used in the CM2.1 series (Gnanadesikan et al., 2006). The lateral friction uses an isotropic Smagorinsky viscosity in mid-latitudes, while within 20 degrees of the equator the anisotropic NCAR viscosity is used, as in the CM2 series. Lateral diffusion of tracers along isopycnals is subject to the thickness diffusion parameterization of Gent and McWilliams (1990) with a spatially varying diffusion coefficient. The time scale in this coefficient depends on the horizontal shear between $100 \mathrm{~m}$ and $2000 \mathrm{~m}$ while the spatial scale is constant. A minimum coefficient of $500 \mathrm{~m}^{2} \mathrm{~s}^{-1}$ and a maximum coefficient of $1200 \mathrm{~m}^{2} \mathrm{~s}^{-1}$ are imposed. The lateral diffusion coefficient for tracers is the same as the lateral diffusion coefficient for thickness. The thickness transport saturates at a value $A_{I} * S_{\max }$ where $S_{\max }$ is set to 0.02 (see Gnanadesikan et al., 2007, for discussion of potential impacts of this parameter). Within the mixed layer, we use the K-profile parameterization of Large et al. (1994). Away from the mixed layer, a background diffusivity of $0.1 \times 10^{-4} \mathrm{~m}^{2} \mathrm{~s}^{-1}$ and a background viscosity of $1 \times 10^{-4} \mathrm{~m}^{2} \mathrm{~s}^{-1}$ is used. Below $500 \mathrm{~m}$, these background coefficients are enhanced by using the scheme of Simmons et 


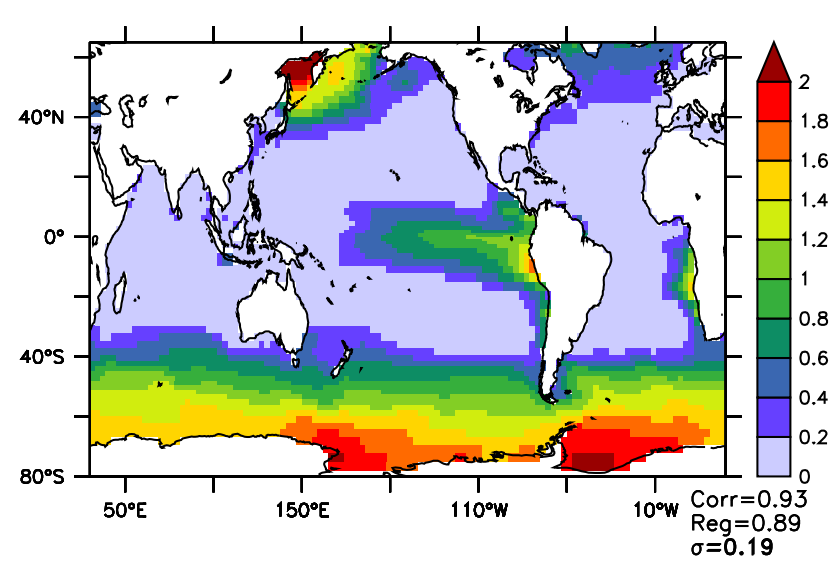

(a) Annual mean $\mathrm{PO}_{4}$, model

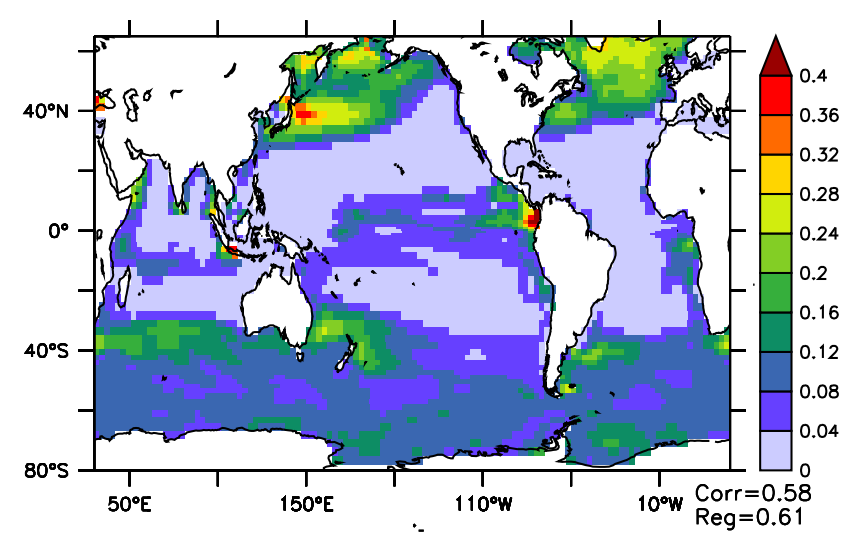

(c) Stand. dev. $\mathrm{PO}_{4}$, model

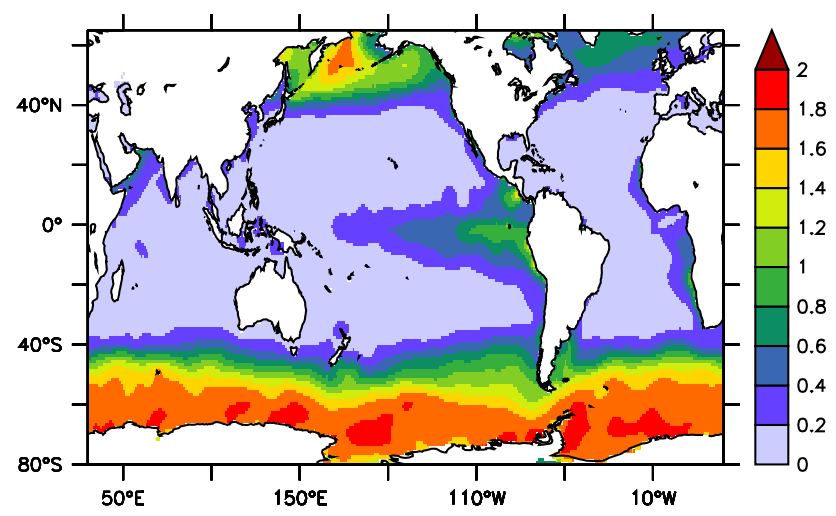

(b) Annual mean $\left(\mathrm{PO}_{4}+\mathrm{NO}_{3} / 16\right) / 2$, WOA01

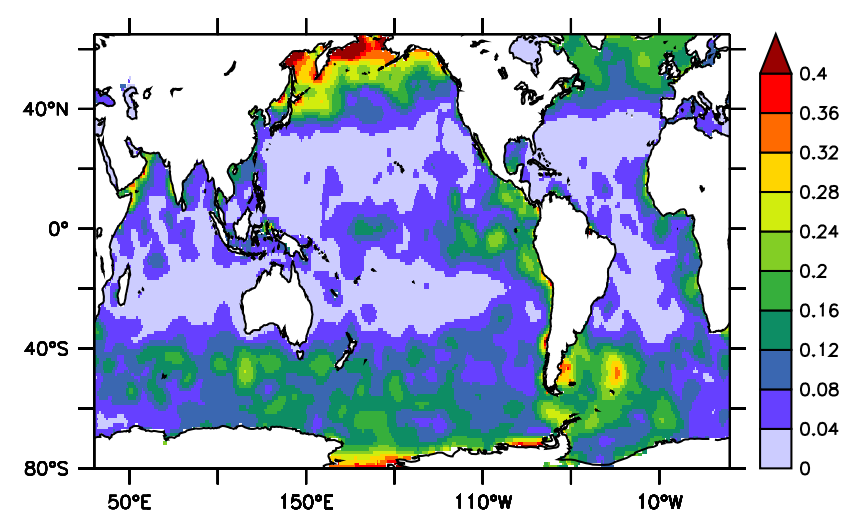

(d) Stand. dev. $\left(\mathrm{PO}_{4}+\mathrm{NO}_{3} / 16\right) / 2$, WOA01

Fig. 4. Macronutrient simulation in BLING-om1p7 (AllVar experiment). (a) Annual mean $\mathrm{PO}_{4}$ concentration from model. (b) Annual mean average macronutrient concentration from observations (WOA01). (c) Annual range of $\mathrm{PO}_{4}$ concentrations, 1 s.d., from one year of monthly model output. (d) Annual range of average macronutrient concentration from observational climatology (WOA01).

al. (2004) to parameterize a tidally-dependent mixing that depends on the in situ stratification as well as prescribed bottom roughness and tidal amplitude.

\subsection{Model simulations}

Because the performance of the biogeochemical model intimately depends on the physical model in which it is embedded, we refer to the coupled ocean-biogeochemical model here as BLING-om1p7. Initial conditions for ocean temperature and salinity were interpolated from the World Ocean Atlas 2001 to the model grid, and the model was started from rest. Phosphate and oxygen concentrations were taken from the World Ocean Atlas 2005. Iron was initialized from a constant global value of $0.6 \mathrm{nM}$ and integrated for 200 years with a preliminary version of the model, to prevent large drift upon initialization. The model was then spun up for 400 years with the AllVar configuration (see below), allowing for the iron cycle and the nutrient structure of the thermocline to come to near equilibrium. A suite of eight experiments was then initialized from this spun-up state, and each was integrated for 400 years. Over the final century RMS changes in surface phosphate were less than $0.01 \mu \mathrm{M}$ and the results after 800 years of integration are essentially identical to those found after 500 years of integration, indicating that we have reached a relatively steady state at the surface for all members of the suite. This suite forms the basis of the discussion in part 3. In all cases, the final year of each run was analyzed.

We describe here the global simulation of the model experiment that includes all three iron limitation terms (which we refer to below as AllVar). The model simulates surface macronutrient concentrations with reasonable fidelity. Note that, although we refer to our limiting macronutrient as " $\mathrm{PO}_{4}$ " (since we do not model denitrification and nitrogen fixation) $\mathrm{NO}_{3}$ tends to limit growth in the ocean, and therefore our " $\mathrm{PO}_{4}$ " is actually more like $\mathrm{NO}_{3}$ in this respect. We therefore compare our modeled $\mathrm{PO}_{4}$ to an 


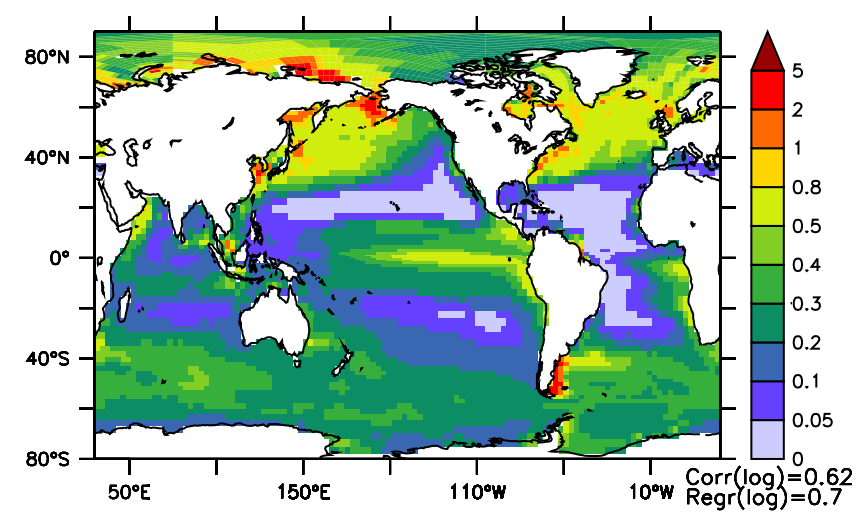

(a) Ann. mean chlorophyll $\left(\mathrm{mg} \mathrm{m}^{-3}\right)$, model

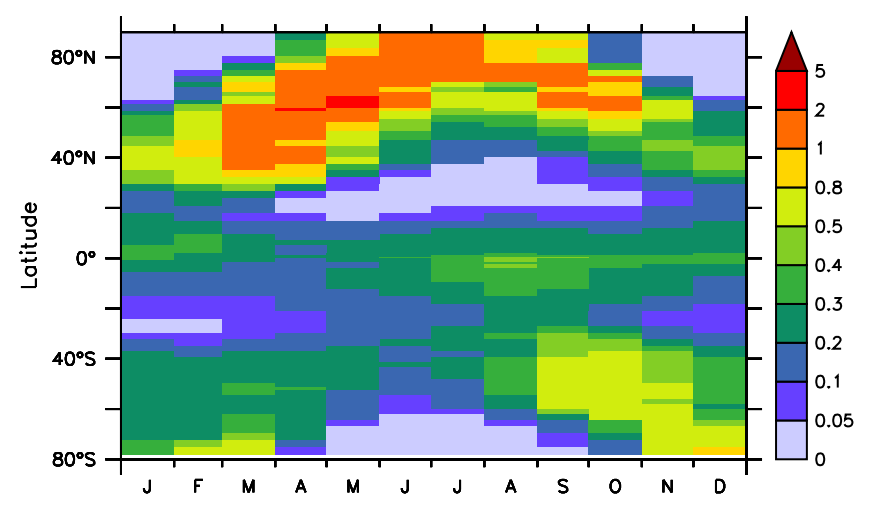

(c) Annual cycle of chlorophyll, model

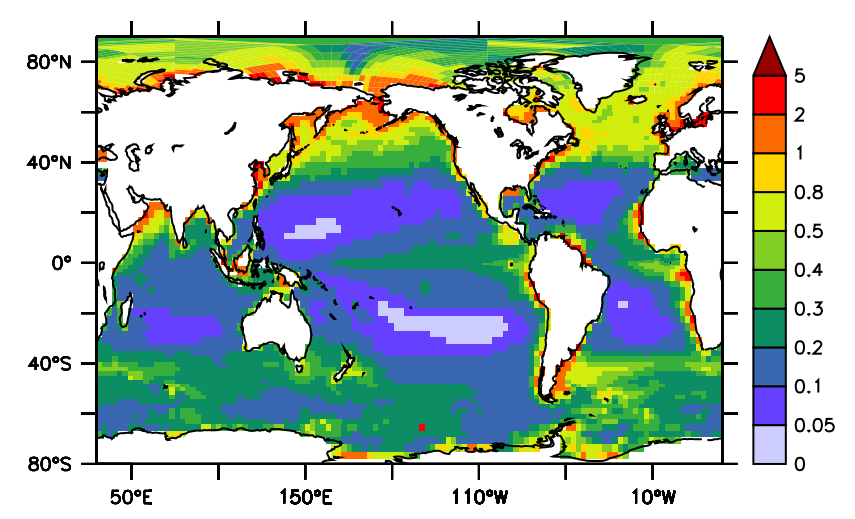

(b) Ann. mean chlorophyll (mg m-3), SeaWIFS

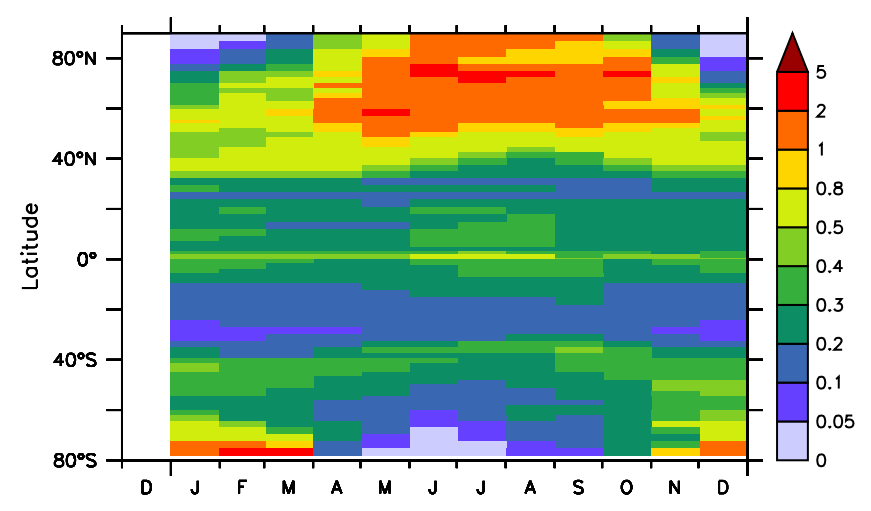

(d) Annual cycle of chlorophyll, SeaWIFS

Fig. 5. Surface chlorophyll, in $\mathrm{mg} \mathrm{m}^{-3}$, simulated by BLING-omlp7 (AllVar experiment) compared with satellite observations. (a) Annual mean chlorophyll, from model. (b) Observed chlorophyll, from SeaWifs (average). (c) Annual cycle of zonally averaged chlorophyll, model. (d) Annual cycle of zonally averaged chlorophyll, SeaWifs climatology (average). Note that the SeaWifs zonal average includes coastal regions with high chlorophyll concentrations, not captured by the model, which is therefore biased low.

"average macronutrient", for which $\mathrm{NO}_{3}$ concentrations are scaled by the Redfield N:P ratio and averaged with $\mathrm{PO}_{4}$, i.e. $\left(\mathrm{PO}_{4}+\mathrm{NO}_{3} / 16\right) / 2$. The last column in Table 2 shows correlation and regression coefficients between the modeled macronutrient and the average macronutrient in this simulation. Correlation and regression coefficients all exceed 0.84 , and the overall patterns of surface macronutrients are generally realistic (Fig. 4a, b). The annual standard deviation of nutrient concentrations (Fig. 4c, d) exhibits a large-scale similarity between modeled concentration and observations, with small ranges in the subtropical gyres and larger ranges along the equator, in the Southern Ocean and in northern subpolar gyres.

As seen in Fig. 5, this experiment also reproduces the contrast between low-chlorophyll gyre centers and the higher chlorophyll upwelling zones and subpolar regions, as seen in satellite observations. The regression coefficient for the log mean chlorophyll concentration is 0.62 , while the correlation coefficient is 0.70 . One of the main sources of error in the chlorophyll simulation arises from the inability of BLINGom $1 \mathrm{p} 7$ to reproduce intense blooms in coastal regions. In addition, the fact that satellite-derived ocean colour products do not represent chlorophyll exclusively, but include coloured dissolved organic matter (e.g. Siegel et al., 2005), could also contribute to the discrepancy.

The simulated surface concentrations of iron (Fig. 6a) range from high values (exceeding $1.5 \mathrm{nM}$ ) in coastal regions, with relatively high values of $0.8-1.0 \mathrm{nM}$ in the dust deposition plumes of the Atlantic and Northern Indian Oceans, similar to the data compilation of Moore and Braucher (2008). Significant seasonal cycles (Fig. 6b) occur over much of the world ocean, with large variations beneath dust plumes, in convective regions and in the western parts of subtropical gyres. These seasonal cycles are due to resupply of iron during deep mixing, removal of iron by sinking particulate organic matter during the growth season, and the seasonal cycle of iron deposition, and likely contribute to small-scale variability in the observational database (Fig. 6a). 


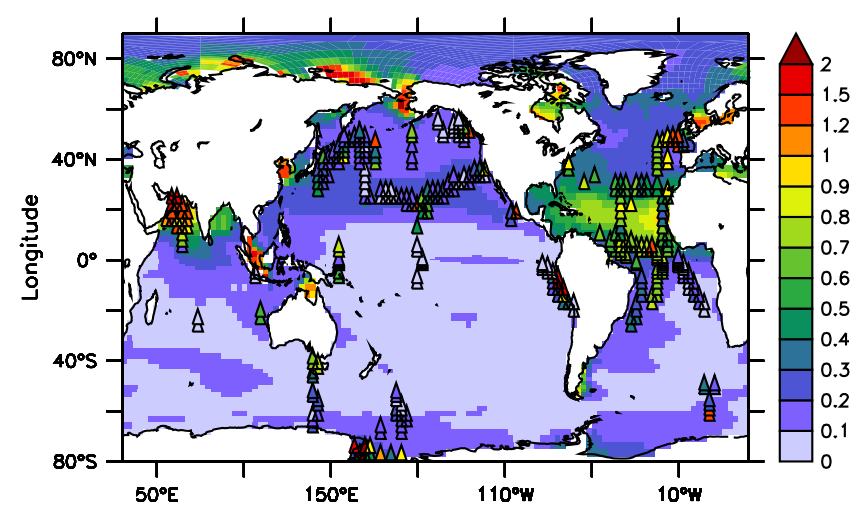

(a) Annual mean surface iron (nM)

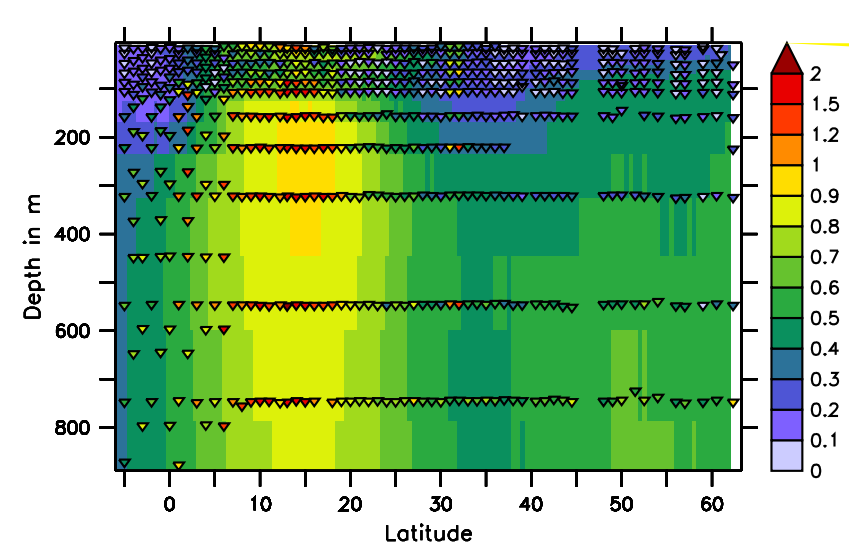

(c) Dissolved iron on $\mathrm{A} 16 \mathrm{~N}$ section

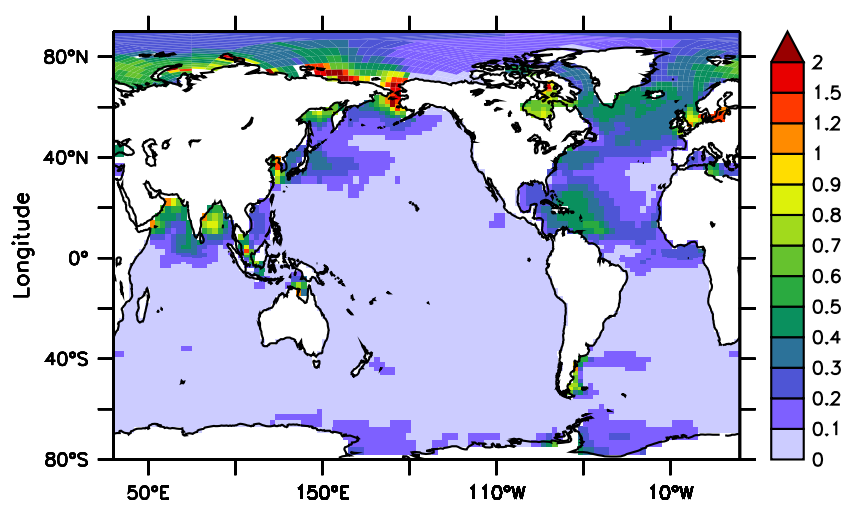

(b) Stand. dev. of surface iron (nM)

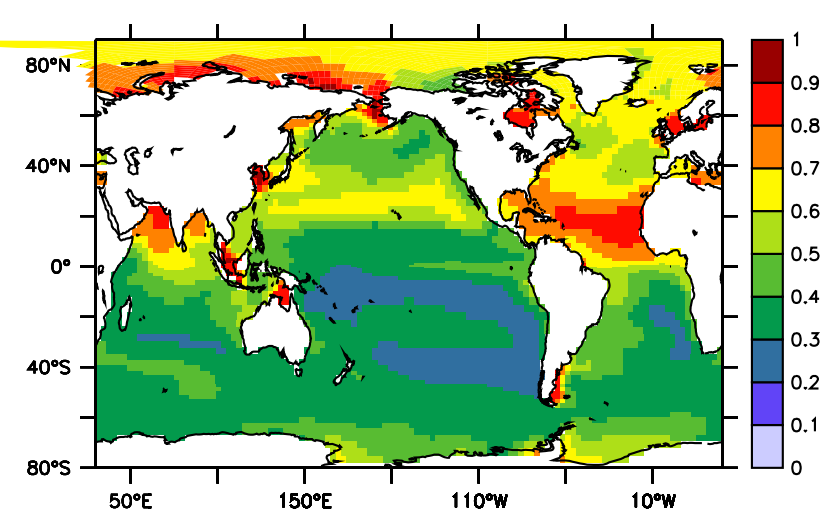

(d) Annual mean surface Def $_{\mathrm{Fe}}$

Fig. 6. Iron simulation in the BLING-om1p7 model (AllVar experiment). (a) Annual average surface iron concentration in nM. Symbols from the compilation of Moore and Braucher (2008), and represent discrete measurements, rather than annual averages. (b) Annual range of modeled iron concentrations, in $\mathrm{nM}$ (difference between local maximum and minimum). (c) Iron along the A16N section in the central Atlantic, symbols from the observations of Measures et al. (2008). (d) Annually averaged iron deficiency term DefFe (Eq. 4).

Measures et al. (2008) recently published a high-resolution section of iron along the A16N track in the central Atlantic. Figure $6 \mathrm{c}$ shows that the model produces a very similar spatial structure with low values in the surface North Atlantic and immediately south of the Equator, with higher values at depth and a plume of high iron north of the equator, centered around $15^{\circ} \mathrm{N}$. Our values are somewhat lower than observed, particularly beneath the Saharan plume, but otherwise the agreement is encouraging given the many uncertainties in the source and sink terms for iron. The correlation between modeled $\log (\mathrm{Fe})$ and that of the Moore and Braucher (2008) compilation is 0.52 , or 0.60 within the upper $100 \mathrm{~m}$. The response of photosynthesis to spatial variations of dissolved iron is given by the term $\operatorname{Def}_{\mathrm{Fe}}$ in the model, presented in Eq. (5). As shown in Fig. 6d, Def $\mathrm{Fe}_{\mathrm{f}}$ is near 1 (no limitation) close to shallow sediments, and near deserts where dust deposition is high. In the northern subpolar gyres it ranges between values of 0.4 and 0.6 while in most of the tropical Pacific and Southern Ocean values of 0.1-0.3 are found.
Iron limitation thus introduces spatial asymmetries between the hemispheres, as well as between the equatorial Atlantic and Pacific Oceans.

Following Gnanadesikan et al. (2004) and Dunne et al. (2007) we compare our model output with three satellitebased primary productivity estimates, developed by Behrenfeld and Falkowski (1997), Carr (2002) and Marra et al. (2003). As seen in Fig. 7a, the Carr (2002) algorithm matches the globally integrated production $(61 \mathrm{GtC}$ vs. $63.4 \mathrm{GtC} / \mathrm{yr}$ ) and time-varying zonal mean production (correlation of 0.75) quite well. The modeled export diverges somewhat more from the observations (Fig. 7b, correlation 0.44 ), being overly dominated by high productivity regions, the physical representation of which may be poorly resolved in our coarse model. Additionally, our model tends to concentrate production and export in subpolar regions during a strong spring bloom, while the satellite-based estimates show more productivity during summertime months. 


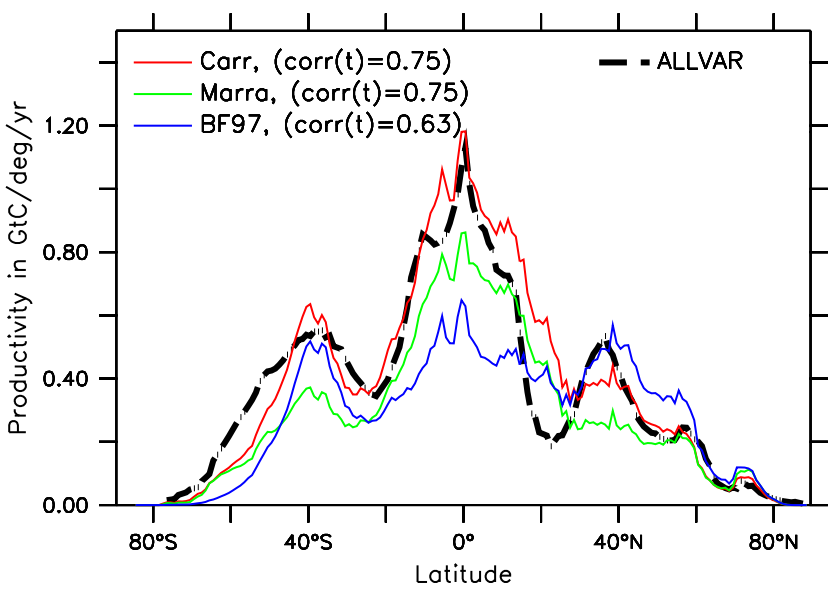

(a) Primary production vs. satellite

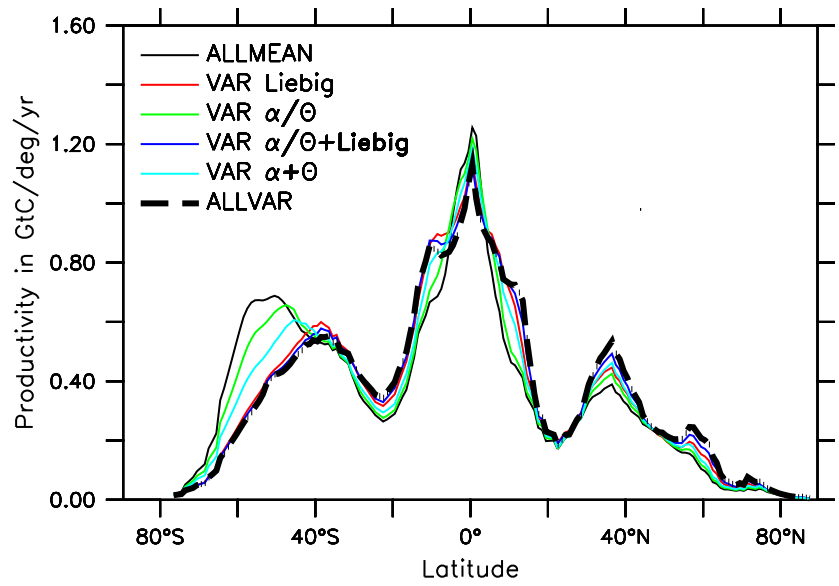

(c) Primary production, experiments

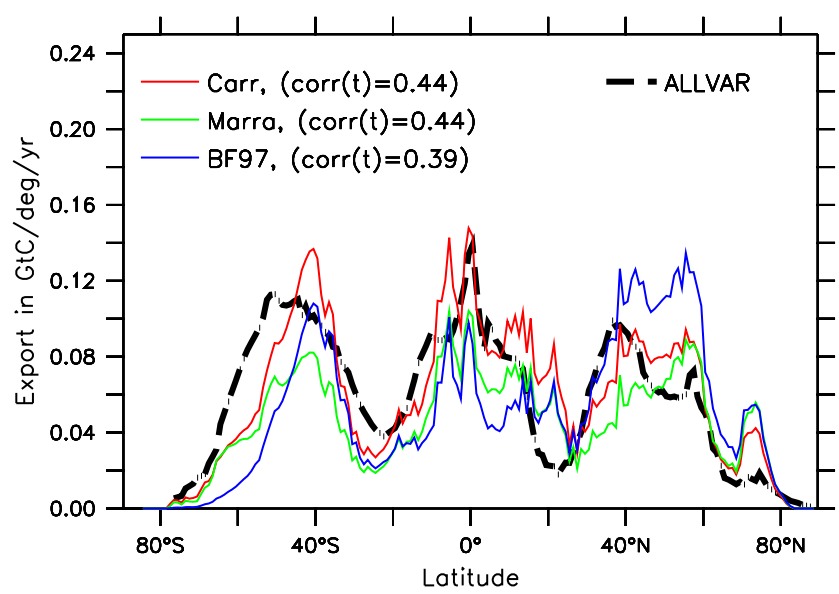

(b) Export production vs. satellite

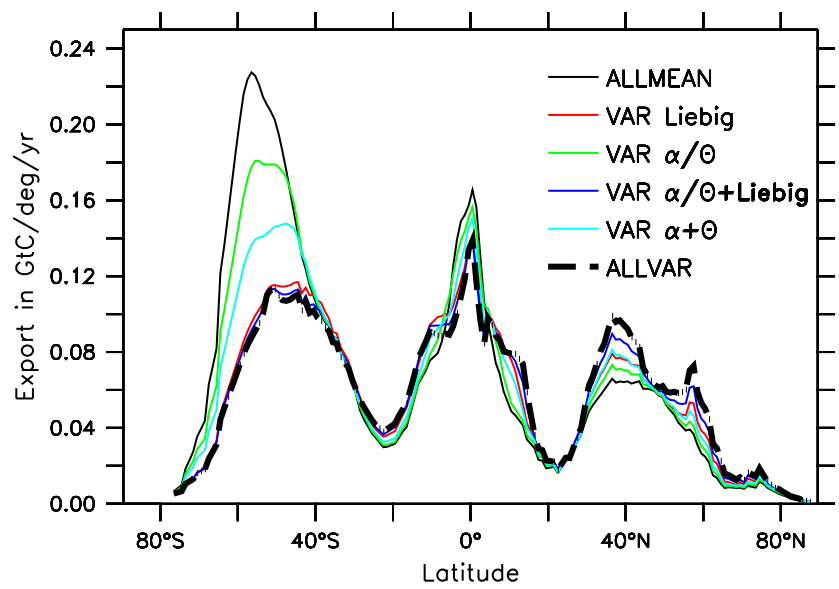

(d) Export production, experiments

Fig. 7. Comparison between modeled and satellite-based estimates of primary productivity and particle export (units of GtC/deg/yr) for BLING-om1p7 AllVar (top panels) and the full suite of experiments (lower panels). Plots show annually integrated values, correlations are for monthly integrated values. (a, b) AllVar vs. satellite-based estimates. (b) AllVar compared to the iron-dependency experiments, as described in the text.

\section{Deconstructing the global response to aspects of iron limitation}

BLING simulates global spatial and temporal variability of dissolved Fe concentrations throughout the ocean, which are then used to calculate $\mathrm{Def}_{\mathrm{Fe}}$. We explore the global biogeochemical response to physiological representations of iron limitation by starting with a version of the model in which the simulated iron concentrations have no effect on photosynthesis, and subsequently introduce an iron dependency to each of the three terms $\alpha^{\mathrm{chl}}, \theta_{\max }^{\mathrm{Fe}}$ and $P_{\mathrm{m}}^{\mathrm{C}}$, both alone and in combination. A model that ignores the effect of iron limitation on any one of the three relevant terms would use something close to the mean value for each, rather than removing the term altogether. We therefore "eliminate" the effect of iron by replacing $\operatorname{Def}_{\mathrm{Fe}}$ with the global mean value. This means that including the effect of iron will cause growth rates to increase in iron-rich regions, and to decrease in iron-poor regions, all else remaining equal. We refer to the run in which the simulated iron has no effect on growth as AllMean, and the run in which all three terms depend on the simulated iron as AllVar (note this is the configuration described in Sect. 2.7, above). The mean $\operatorname{Def}_{\mathrm{Fe}}$ is determined from the fifth century of the AllVar run (equal to 0.4595). Intermediate between AllMean and AllVar are $\operatorname{Var} \alpha, \operatorname{Var} \theta$ and $\operatorname{Var}-$ Liebig, in which iron affects only one of $\alpha^{\mathrm{chl}}, \theta_{\max }^{\mathrm{Fe}}$ and $P_{\mathrm{m}}^{\mathrm{C}}$, respectively, and $\operatorname{Var} \alpha+\theta$, $\operatorname{Var} \theta+$ Liebig and $\operatorname{Var} \alpha+$ Liebig, in which all but one of the three parameters depends on the simulated iron concentrations. It is important to recognize that $\alpha^{\mathrm{chl}}$ and $\theta_{\max }^{\mathrm{Fe}}$ have numerically identical effects on $I_{\mathrm{k}}$ in 


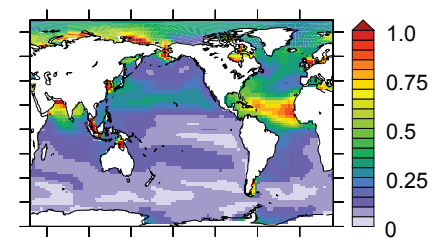

(a) AllMean

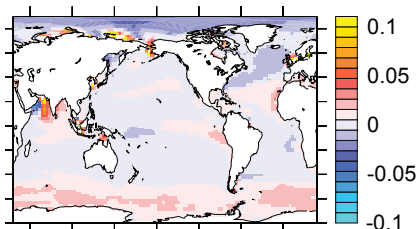

(b) $\operatorname{Var} \alpha / \theta$ - AllMean

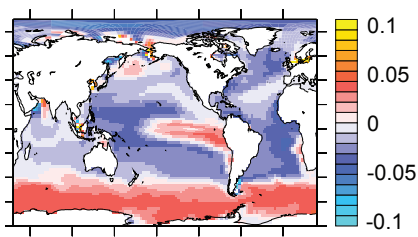

(c) VarLiebig - AllMean

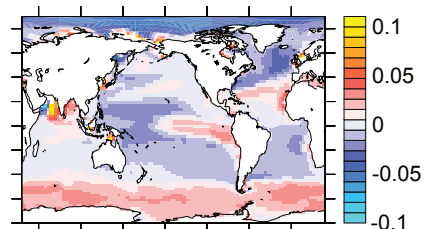

(d) $\operatorname{Var} \alpha+\theta-$ AllMean

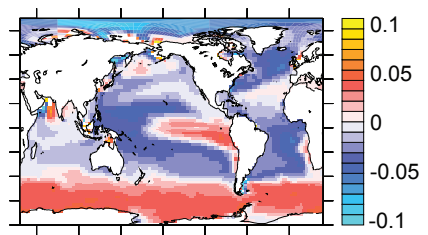

(e) Var $\alpha / \theta+$ Liebig - AllMean

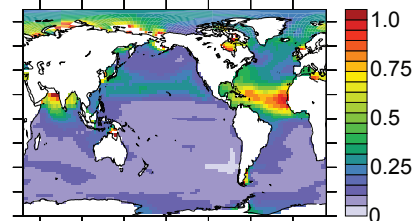

(f) AllVar

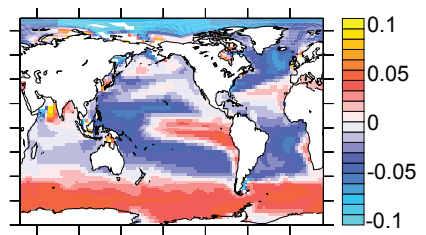

(g) AllVar - AllMean

Fig. 8. Impact of including iron dependency terms on global, annual mean surface dissolved iron concentrations (in nM). Panels (a) and (g) show simulated concentrations, whereas panels (b-e) and (g) show differences between the experiment indicated and the AllMean experiment.

our formulation (and given our parameter choices), such that their product essentially represents the efficiency with which incident light is harvested by the phytoplankton. Hence, we present the results for the two as interchangeable (with the exception of their impacts on chlorophyll, which differ).

The lower panels of Fig. 7 show the global impact of including iron dependencies on primary production and export production. Unsurprisingly, the interhemispheric asymmetry in iron supply causes primary productivity to decrease in the iron-poor Southern Hemisphere, and to increase in the Northern Hemisphere, for all iron limited runs, relative to AllMean (Fig. 7c). All iron-dependent runs also show a slight decrease in primary productivity on the equator, though more pronounced is a meridional widening of the high-productivity zone, reducing the disagreement with satellite estimates. Meanwhile, changes in particle export follow a similar pattern but show extreme differences in the Southern Ocean - though striking, this simply follows from the nonlinear increases of biomass and particle export with increasing growth rates.

However, a surprising response is evidenced in the relative sensitivities of different iron limitation terms. In the Northern Hemisphere, the subsequent inclusion of each additional iron dependency causes the export to increase, such that each term appears to be of roughly equivalent importance. In contrast, within the Southern Hemisphere, the inclusion of the light-harvesting efficiency terms ( $\operatorname{Var} \alpha$ and $\operatorname{Var} \theta$ ) only have an impact when VarLiebig is not included. All simulations including an iron-dependent light-saturated growth rate (VarLiebig, $\operatorname{Var} \theta / \alpha+$ Liebig and AllVar) are nearly indistinguishable. This begs the question, why does an iron dependency in the light-saturated growth rate (VarLiebig) overwhelm the iron dependency of the light harvesting efficiency (Var $\alpha$ and $\operatorname{Var} \theta$ ), and why is this so pronounced in the Southern Ocean?
To understand the results of the experiments we undertake a more detailed analysis, beginning with the impact of variable iron limitation on the surface dissolved iron field. Figure 8a shows the dissolved iron concentration predicted by the model when growth rates are not limited by the local iron concentration, but only the global average value. When spatially and temporally varying iron limitation affects one or more growth parameters, the general result is to reduce the amplitude of global variations. This is because iron uptake rates decrease in iron-limited areas where growth rates are low (thus increasing the quantity of iron in such regions), and increase in iron-rich areas where growth rates are high (thus decreasing the quantity of iron in such regions). The effect of including multiple iron limitation mechanisms produces a nearly additive increase in the magnitude of this effect, with the largest contribution coming, once again, from the Liebig term. This negative feedback, however, means that the changes to the iron cycle buffer, rather than explain, the modeled pattern of changes.

Iron-dependence of the Liebig term also shows a powerful influence on the surface $\mathrm{PO}_{4}$ field. As shown in Fig. 9b, the AllMean simulation greatly underestimates surface $\mathrm{PO}_{4}$, relative to observations, in the Southern Ocean, eastern equatorial Pacific, and subarctic Pacific. Including an iron dependency in any of the three photosynthesis terms, in any combination, reduces the total error relative to observations (see also Table 2). However, the strongest effect is clearly associated with the light-saturated photosynthesis term, VarLiebig (Fig. 9d), which greatly outweighs the significance of the other terms - again, particularly in the Southern Ocean, as shown in the zonal mean (Fig. 7). This suggests that either our formulation has placed too much weight behind the VarLiebig term, or that the net result of including multiple limitations tends to largely eliminate the impacts of photosynthetic efficiency on the surface nutrient field. 


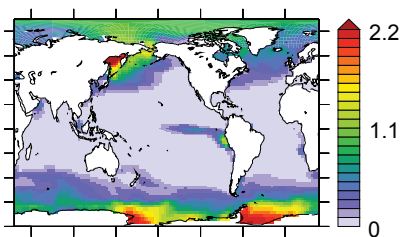

(a) AllMean

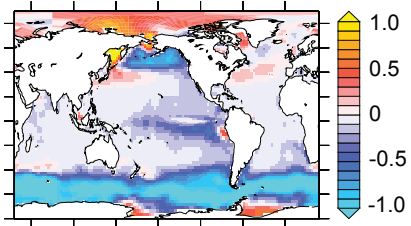

(b) AllMean - Obs

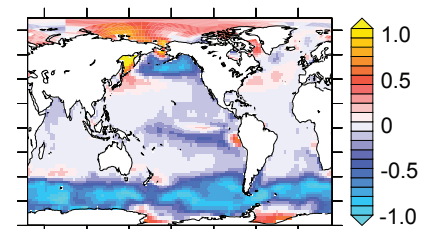

(c) $\operatorname{Var} \alpha / \theta$ - Obs

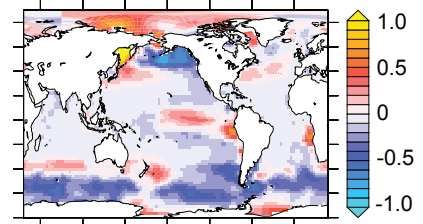

(d) VarLiebig - Obs

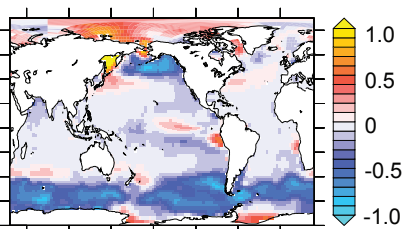

(e) $\operatorname{Var} \alpha+\theta-$ Obs

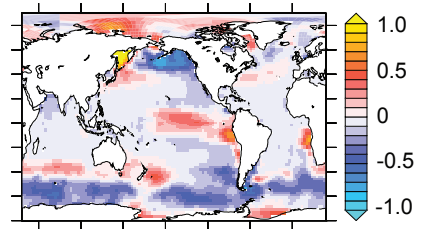

(f) $\operatorname{Var} \alpha / \theta+$ Liebig - Obs

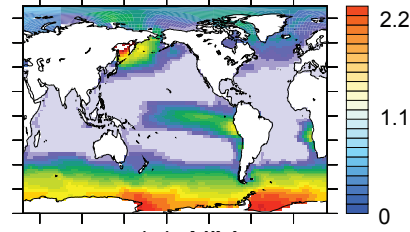

(g) AllVar

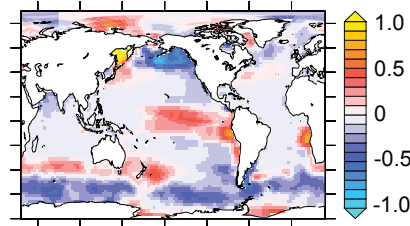

(h) AllVar - Obs

Fig. 9. Impact of including iron dependency terms on global, annual mean surface dissolved $\mathrm{PO}_{4}$ concentrations (in $\mu \mathrm{M}$ ). Panels (a) and (g) show simulated concentrations, whereas panels $(\mathbf{b}-\mathbf{f})$ and (h) show differences between the experiment indicated and the average macronutrient, calculated from observations (WOA01).

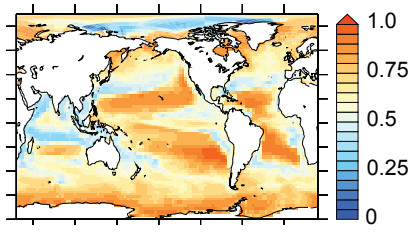

(a) AllMean

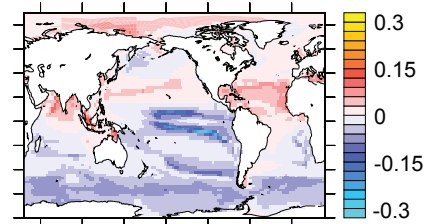

(b) $\operatorname{Var} \alpha / \theta$ - AllMean

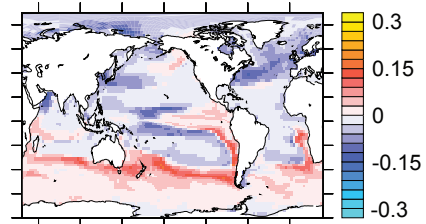

(c) VarLiebig - AllMean

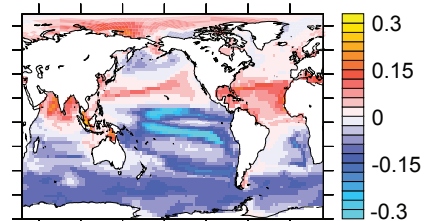

(d) Var $\alpha+\theta-$ AllMean

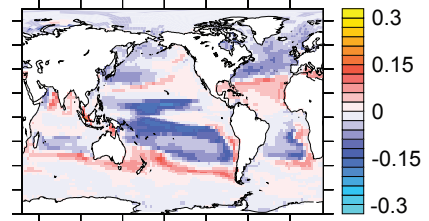

(e) Var $\alpha / \theta+L i e b i g$ - AllMean

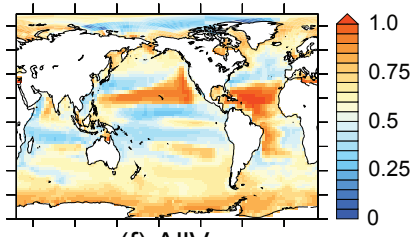

(f) AllVar

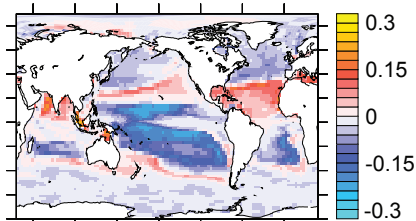

(g) AllVar - AllMean

Fig. 10. Impact of including iron dependency terms on annually-averaged light limitation (where 1 is no light limitation), vertically-weighted by phosphorus uptake rates. This therefore reflects the severity of light limitation at the depth where most growth is occurring in the water column. Panels (a) and (f) show simulated limitations, whereas panels (b-e) and (g) show differences between the experiment indicated and the AllMean experiment, such that red colours indicate less light-limitation then AllMean, while blue colours indicate more light limitation.

The photosynthetic efficiency terms (Var $\alpha$ and $\operatorname{Var} \theta)$ do have a significant impact on light limitation (Fig. 10), as expected, causing changes that are of approximately the same magnitude as those of VarLiebig (Fig. 10b vs. 10c). However, they are dominantly of the opposite sign of the VarLiebig changes. In the VarLiebig case (Fig. 10c), the reduction of $P_{\mathrm{m}}^{\mathrm{C}}$ within iron-limited domains actually causes a decrease in the severity of light limitation (e.g. in the Southern Ocean). Thus, if the ability to synthesize chlorophyll and photosynthetic reaction centers is unaffected by iron concentrations, the sole effect of iron limitation is to decrease the light-saturated photosynthesis rate $P_{\mathrm{m}}^{\mathrm{C}}$, thereby decreasing the demand for light. In contrast, including iron dependencies in only the photosynthetic efficiency terms (Fig. 10b, d) clearly exacerbates light limitation in regions with low $\mathrm{Def}_{\mathrm{Fe}}$, more consistent with observations (Maldonado et al., 1999; Hiscock et al., 2008).

The net result, in the global simulation, reveals interacting effects of the light-saturated and photosynthetic efficiency terms. Most notably, the importance of photosynthetic efficiency on the Southern Ocean is almost entirely muted when the light-saturated growth rate is also affected by iron (Fig. 10, panels e and g). This is because the light limitation term of Eq. (2), $P_{\mathrm{m}}^{\mathrm{C}} / \alpha^{\mathrm{chl}} \theta_{\max }^{\mathrm{Fe}}$, becomes vanishingly small as iron becomes very limiting in the Liebig component of $P_{\mathrm{m}}^{\mathrm{C}}$, an effect that is further exaggerated due to the low temperatures of the Southern Ocean (making $P_{\mathrm{m}}^{\mathrm{C}}$ even smaller). Thus, the tendency for photosynthetic efficiency to deteriorate under extreme iron limitation is rendered insignificant by the low energy demand at the very low inherent growth 


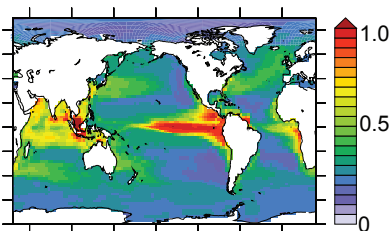

(a) AllMean

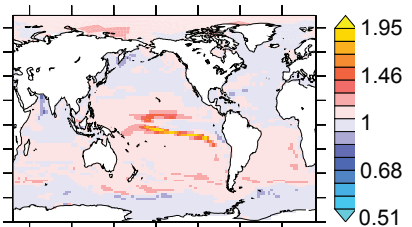

(b) $\operatorname{Var} \alpha / \theta /$ AllMean

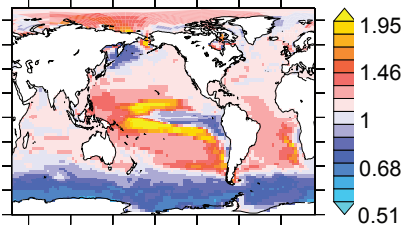

(c) VarLiebig / AllMean

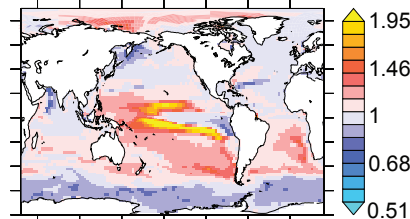

(d) $\operatorname{Var} \alpha+\theta$ / AllMean

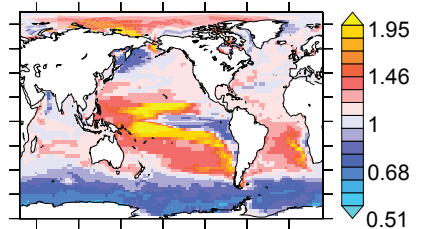

(e) $\operatorname{Var} \alpha / \theta+$ Liebig / AllMean

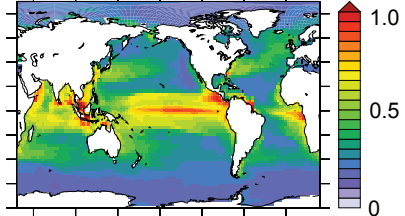

(f) AllVar

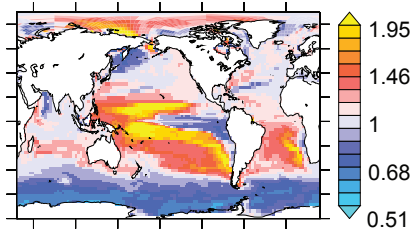

(g) AllVar / AllMean

Fig. 11. Impact of including iron dependency terms on annually-averaged growth rate $\left(P^{\mathrm{C}}\right)$, vertically-weighted by phosphorus uptake rates. Panels (a) and (f) show simulated rates $\left(\mathrm{d}^{-1}\right)$. Panels (b) to (e) and (g) show the ratios of growth rates for the experiment indicated to that of the AllMean experiment, such that red colours indicate faster growth rates and blue colours indicate slower growth rates.

rates. In contrast, in relatively warm waters where iron is more abundant, the light limitation term $P_{\mathrm{m}}^{\mathrm{C}} / \alpha^{\mathrm{chl}} \theta_{\max }^{\mathrm{Fe}}$ is relatively large, providing increased leverage to variability of $\alpha^{\text {chl }}$ and $\theta_{\max }^{\mathrm{Fe}}$ and thereby accentuating the importance of iron for light harvesting. This is evident in the enhanced light limitation in the tropical Pacific, off equator, which persists when VarLiebig is included (Fig. 10, panels b and d vs. e and g). In physiological terms, the inherent ability of phytoplankton to grow more quickly in warm waters gives them a greater demand for usable electrons, and therefore makes them more dependent on efficient photosynthetic machinery. We point out that this prediction arises directly from our theoreticallybased inclusion of iron limitation in the Geider photoadaptation framework; its relevance should be tested by field and laboratory experiments.

However, despite the fact that the tropical Pacific becomes much more light limited when photosynthetic efficiency depends on iron concentrations, this region actually experiences an increase in growth rates in these same simulations (Fig. 11b, d). This occurs because overall growth rates are not just a function of light and iron limitation but also of macronutrient availability, which is modulated by ocean circulation and nutrient cycling, presenting non-local effects. In the tropical Pacific (off-equator), the supply of $\mathrm{PO}_{4}$ to this otherwise $\mathrm{P}$-starved region is increased by greater leakage from the equatorial Pacific, even as the latter region becomes more iron limited (compare Figs. 10b, d with 11b, d), an effect previously discussed by Dutkiewicz et al. (2005). Essentially, the increase of maconutrient abundance in this region, caused by iron limitation upstream, more than compensates for the enhanced light limitation.

These nuances help to explain the finding, pointed out in Fig. 7, that the effect of iron on photosynthetic efficiency is almost completely overwhelmed by that of the Liebig term, outside of the northern oceans. In these latter regions, greater iron availability allows phytoplankton to grow more quickly, making them more hungry for light and therefore more sensitive to the photosynthetic efficiency terms, as revealed by the responses to $\operatorname{Var} \alpha$ and $\operatorname{Var} \theta$. Meanwhile, near tropical upwellings, decreases in photosynthetic efficiency are counterbalanced by large increases in macronutrient availability, which end up dominating changes in growth rate. Finally, in the Southern Ocean, where phytoplankton are burdened by low temperatures and scarce iron, the low light-saturated photosynthesis rates mean that the plankton do not need a lot of light, and thus show little additional response to Var $\alpha$ and $\operatorname{Var} \theta$. This leads to the counterintuitive result that when iron is most scarce, its effect on photosynthetic efficiency has the least impact on biogeochemistry.

Importantly, the greater impact of photosynthetic efficiency on production in the Northern Hemisphere (Fig. 7) is not due to an overall increase in annually averaged growth rates (compare panels $11 \mathrm{c}$ and $11 \mathrm{~g}$ ). Instead, it acts through modulation of the seasonal cycle. As shown in Fig. 12a, the annual cycle of productivity in the North Atlantic $\left(70^{\circ} \mathrm{W}-0^{\circ}\right.$, $50^{\circ} \mathrm{N}-65^{\circ} \mathrm{N}$ ) reveals distinct impacts from all three limitation terms. All contribute to intensifying the spring bloom and shifting it earlier, due to the relative abundance of iron resupplied from below by deep winter mixing, and to suppressing production during summer, due to more rapid nutrient depletion. Because of the strong degree of nonlinearity between growth and export, a more intense spring bloom produces a much higher annually integrated particle export. Surface chlorophyll (Fig. 12b) shows a similar pattern, with the exception that increased growth rates in experiments including Var $\alpha$ are compensated by a lower chl:C ratio, so that $\alpha^{\mathrm{chl}}$ has little impact on chlorophyll. In contrast, in the Southern Ocean $\left(80^{\circ} \mathrm{S}-50^{\circ} \mathrm{S}\right)$, the inclusion of regionally dependent iron limitation suppresses growth rates, and prevents strong blooms. Inclusion of an iron dependency on 


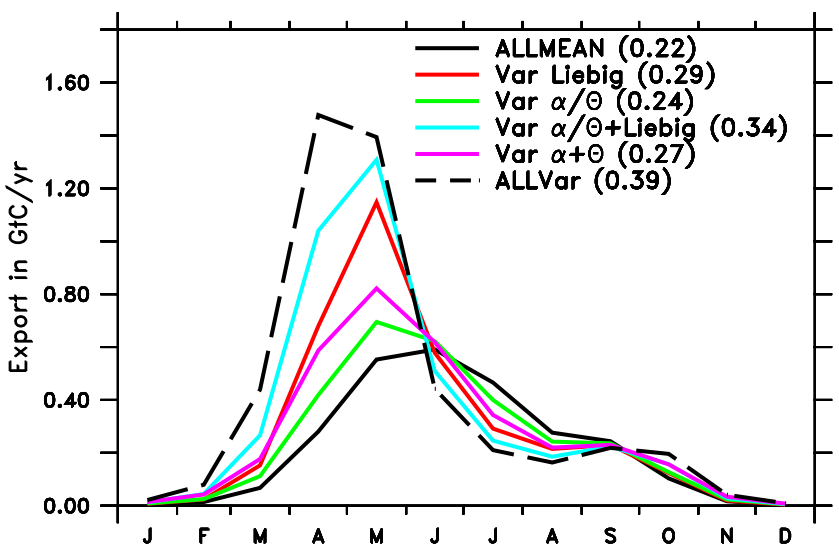

(a) N Atlantic export production

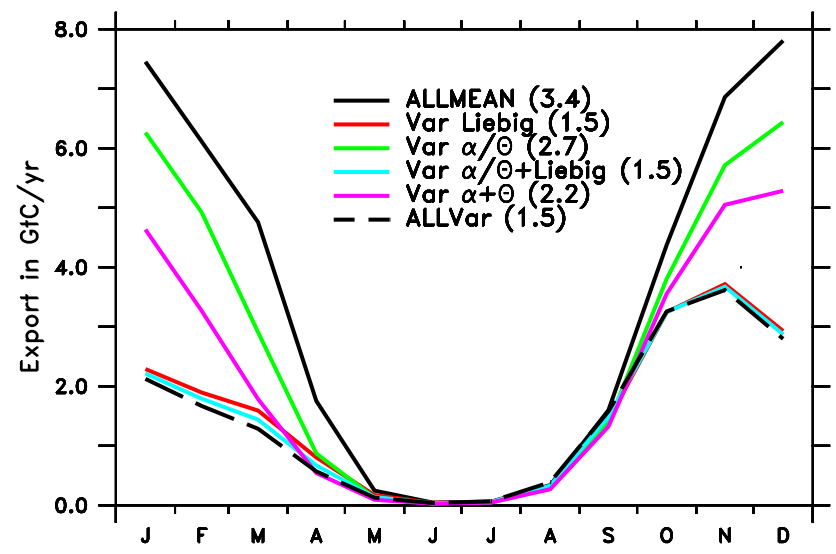

(c) Southern ocean export production

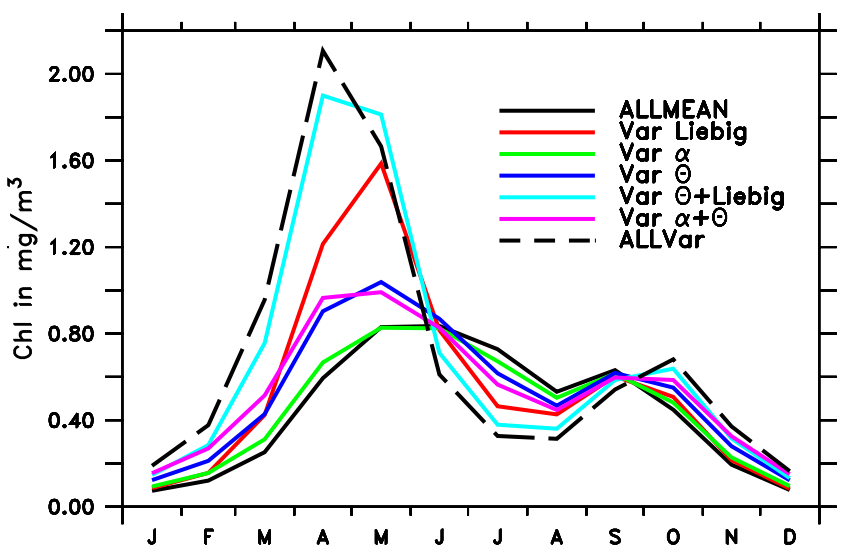

(b) N Atlantic surface chlorophyll

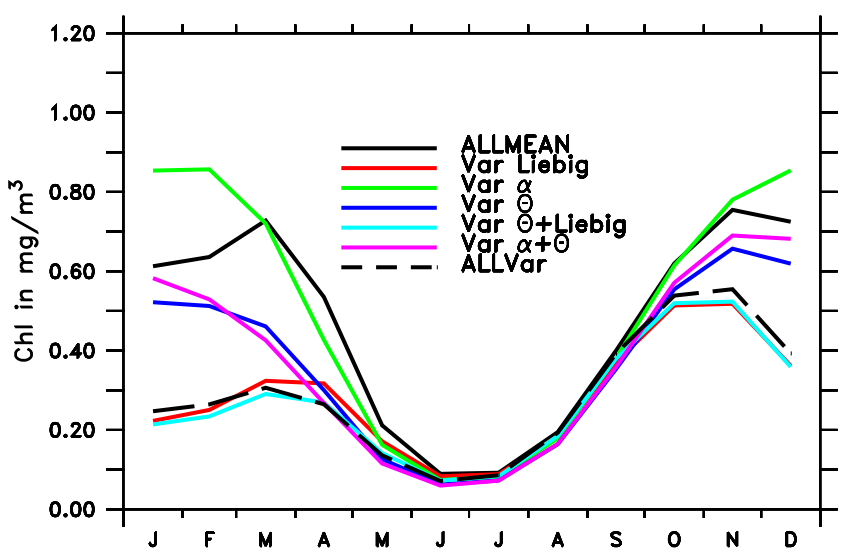

(d) Southern ocean surface chlorophyll

Fig. 12. Impact of including iron dependency terms on the seasonal cycles of export production at $80 \mathrm{~m}$ and surface chlorophyll. (a) Particle export in GtC/yr, subpolar North Atlantic ( $70 \mathrm{~W}-0 \mathrm{~W}, 50-65 \mathrm{~N})$. Annually integrated values shown in parentheses. (b) Surface chlorophyll in $\mathrm{mg} \mathrm{m}^{-3}$, subpolar North Atlantic. (c) Particle export in GtC/yr, subpolar/polar Southern Ocean (80 S-50 S). Annually integrated values shown in parentheses. (d) Surface chlorophyll in $\mathrm{mg} \mathrm{m}^{-3}$, subpolar Southern Ocean.

the maximum light-saturated photosynthesis rate, in experiment Var Liebig (red line), has a large impact on the seasonal cycle, so that $\operatorname{Var} \alpha+$ Liebig, $\operatorname{Var} \theta+$ Liebig (light blue line) and AllVar (dashed black line) are essentially identical to VarLiebig. As discussed above, this reflects the relatively low utility of light to cells with low maximum photosynthesis rates, arising from the cold waters and perennial ironlimitation of $P_{\mathrm{m}}^{\mathrm{C}}$, so that photosynthetic efficiency has little role to play. Surface chlorophyll (Fig. 12d) shows more of a temporal impact as iron deficiency is added, with the more iron-limited cases showing a dip in chlorophyll as iron limitation impedes chlorophyll synthesis during the very irondepleted summer.

The impact of photosynthetic efficiency on primary productivity also exhibits a different vertical structure from the Liebig term, as illustrated in Fig. 13. In the subpolar
Southern Ocean, adding spatiotemporal iron limitation to the Liebig term slows primary production uniformly by about $35 \%$ in the well-lit surface layers, but has little impact below that (red line, Fig. 13a). The impact of iron on photosynthetic efficiency is greatest at about $60 \mathrm{~m}$, with a decrease of about $20 \%$ for either $\alpha$ or $\theta$ alone, or $40 \%$ for both, comparable to the Liebig term, for both together (Fig. 13a). Because, however, most of the production occurs above in the top few layers in our model, the effect of iron on the cumulative integrated primary production is dominated by the Liebig term (Fig. 13b). In the Northern Hemisphere subpolar gyres, adding spatiotemporal iron limitation has the opposite effect, increasing iron availability and causing growth rates to increase. Here the Liebig term has a relatively homogenous impact with depth, increasing primary productivity by 15-20\%. However, the inclusion of iron limitation in the 


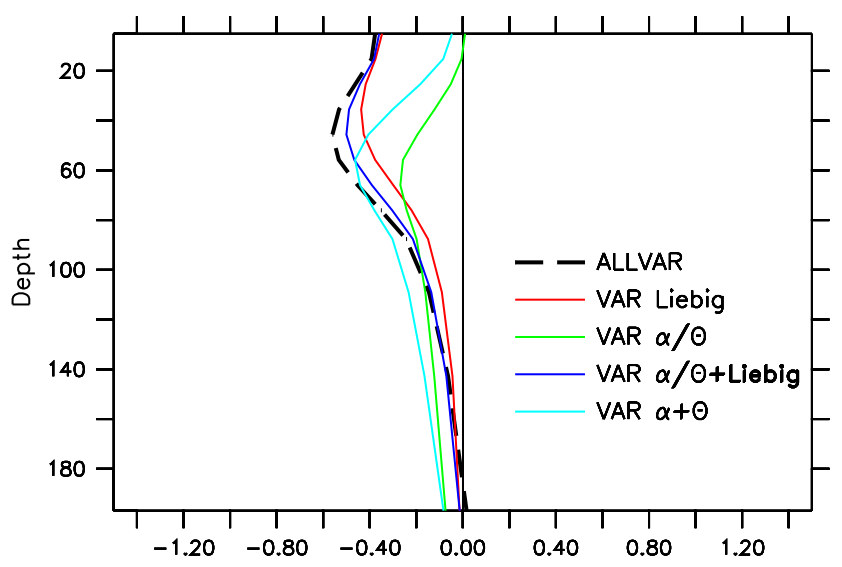

(a) $\ln (\mathrm{PP} / \mathrm{AllMean} \mathrm{PP})$, South

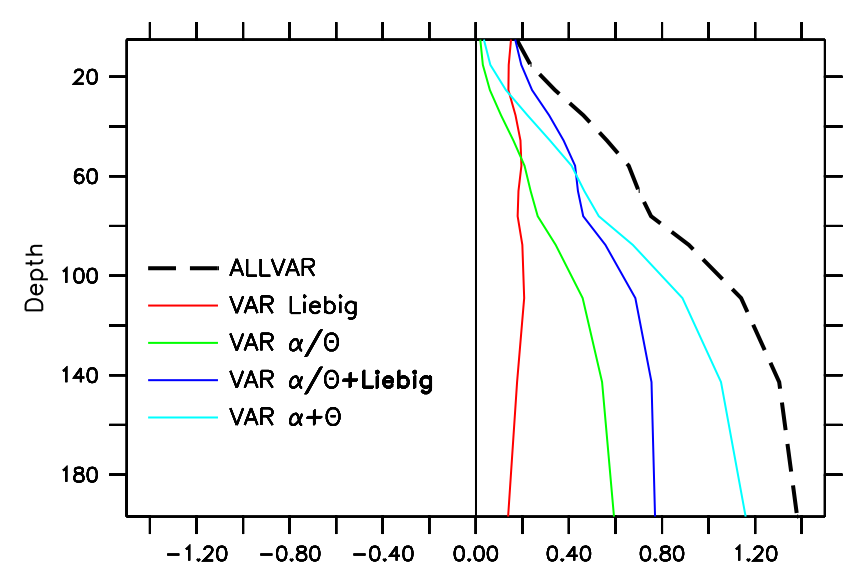

(c) $\ln ($ PP/AllMeanPP), North

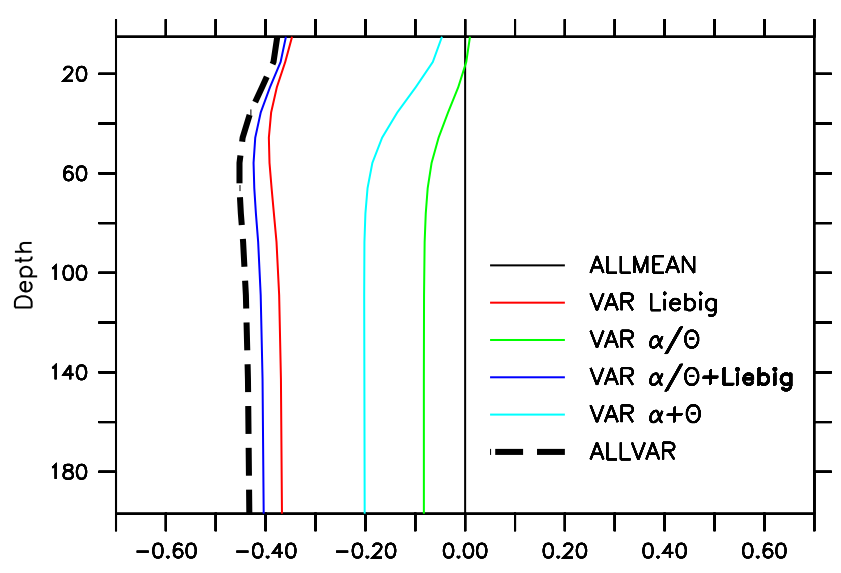

(b) $\ln$ (cumul.PP/cumul.AllMeanPP), South

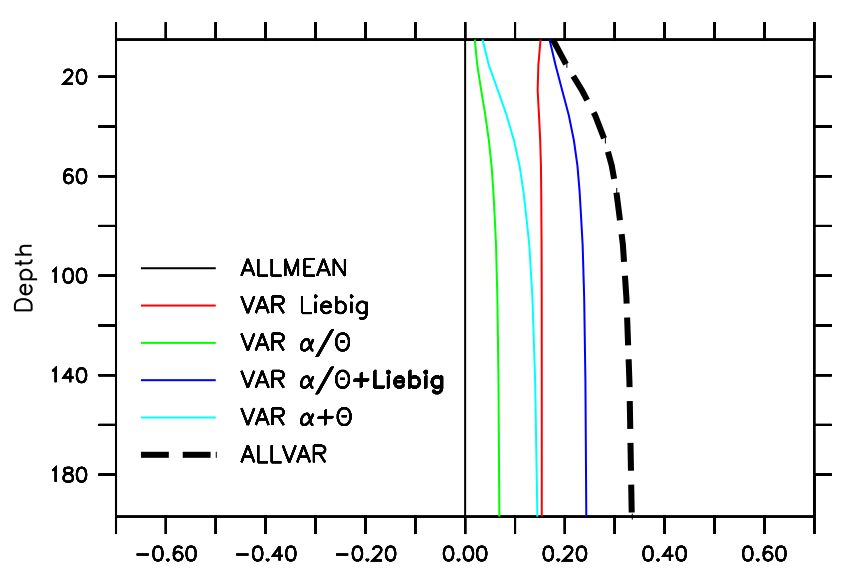

(d) In(cumul.PP/cumul.AllMeanPP), North

Fig. 13. Impact of including iron dependency terms on the vertical profiles of primary productivity in the northern and southern high latitudes. (a) Natural logarithm of the ratio of primary productivity to that computed by AllMean model for $65 \mathrm{~S}-40 \mathrm{~S}$. Above $30 \mathrm{~m}$ most of the impact is from iron limitation of growth, while below that depth iron limitation of light becomes important. (b) Natural logarithm of the ratio of cumulatively integrated primary production above a given depth to that computed for the AllMean model, 65 S-40 S. (c) Same as (a) but for 40 N-65 N. (d) Same as (b) but for 40 N-65 N.

photoadaptation terms drive large increases with depth, increasing production in the deep ocean by $80 \%$ for either $\alpha$ or $\theta$ alone, or more than doubling it for both together. As a result, the primary production at $200 \mathrm{~m}$ depth in the AllVar run is more than three times that of the AllMean run (Fig. 13c). Nonetheless, since the bulk of the productivity occurs above $60 \mathrm{~m}$, as in the Southern Hemisphere, this contributes relatively little to the integrated water column primary production.

\section{Conclusions}

We have developed a simplified model of oceanic biogeochemical cycling built upon the photoadaptation model of Geider et al. (1997) and the biogeochemical algorithms of particle export developed by Dunne et al. (2005). The resulting model, BLING, simulates phytoplankton growth rates from instantaneous macronutrient and micronutrient concentrations, temperature, and light limitation. Then, through a parameterization of ecosystem processes, BLING uses those growth rates in order to determine biomass, uptake, dissolved organic matter production and the export of sinking particles. Embedded in a general circulation model of the ocean, BLING reproduces many features of the large-scale nutrient and chlorophyll fields, but because it uses relatively few prognostic tracers it does not greatly increase the computational cost of running the model.

We used this model to explore the impacts of variously applying iron dependencies to the light-saturated photosynthesis rate $\left(P_{\mathrm{m}}^{\mathrm{C}}\right)$ as a Liebig limitation with $\mathrm{PO}_{4}$, to the efficiency with which each unit of chlorophyll produces 


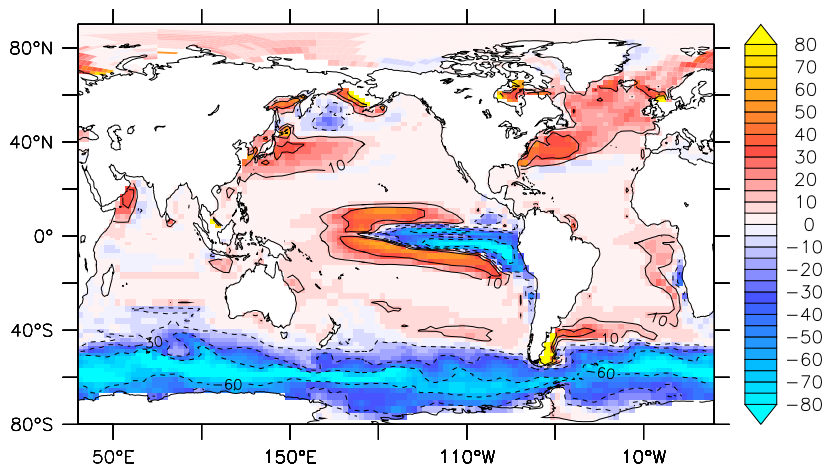

(a) Change in export, linear sum $\left(\mathrm{g} \mathrm{C} \mathrm{m}^{-2} \mathrm{a}^{-1}\right)$

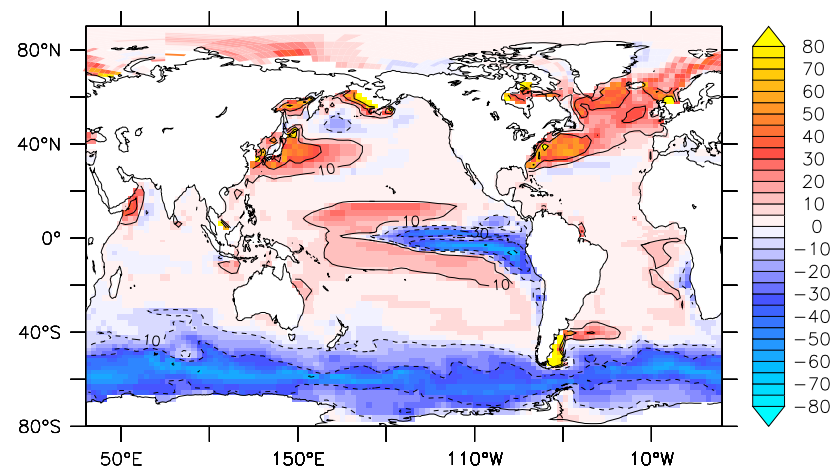

(b) Change in export, AllVar-AllMean $\left(\mathrm{g} \mathrm{C} \mathrm{m}^{-2} \mathrm{a}^{-1}\right)$

Fig. 14. Interactive effects of photosynthetic terms on global carbon export production (vertical flux at $100 \mathrm{~m}$ ). (a) The linear sum of changes caused by photosynthetic efficiency terms and the light-saturated photosynthesis term, i.e. (Var $\alpha+\theta-$ AllMean) + (VarLiebig-AllMean). (b) The actual simulated change in export when all three terms are simultaneously included, i.e. AllVar-AllMean. If the terms operated independently, the two panels would be identical. Where the amplitude is reduced in (b) relative to (a), a decrease in the light-saturated photosynthesis rates is reducing the sensitivity to photosynthetic efficiency. Conversely, where changes in (b) are amplified relative to (a), an increase in light-saturated photosynthesis rates is enhancing the sensitivity to photosynthetic efficiency, so that the net result is larger than otherwise expected.

usable electrons at low levels of light $\left(\alpha^{\text {chl }}\right)$, and to the ability of the plankton to synthesize chlorophyll, $\theta_{\max }^{\mathrm{Fe}}$. In general, including iron-dependent photosynthesis terms reduced growth rates in macronutrient-rich regions (primarily the Southern Ocean, equatorial Pacific, and subarctic Pacific) and allowed macronutrients to leak to neighbouring oligotrophic regions, increasing growth rates there (Fig. 11f). Including an iron dependency of $P_{\mathrm{m}}^{\mathrm{C}}$ (experiments with VarLiebig) had the largest effect on all aspects of the simulation. This included a remarkably large effect on light limitation, through iron limitation of $P_{\mathrm{m}}^{\mathrm{C}}$, shrinking the first term of Eq. (2), $P_{\mathrm{m}}^{\mathrm{C}} / \alpha^{\mathrm{chl}} \theta_{\max }^{\mathrm{Fe}}$ and thereby mitigating iron-light colimitation. In physiological terms, this represents a reduction in the usefulness of light to a phytoplankton community whose light-saturated growth rates are severely restricted by a lack of $\mathrm{Fe}$, even when the ability to harvest light is itself hampered by iron-limited decreases of $\alpha^{\text {chl }}$ and/or $\theta_{\max }^{\mathrm{Fe}}$. This general tendency seems to be supported by at least one laboratory experiment, carried out with a Chaetoceros diatom (Davey and Geider, 2001), for which changes in chlorophyll-normalized $P_{\mathrm{m}}^{\mathrm{C}}\left(\right.$ i.e. $\left.P_{\mathrm{m}}^{\mathrm{B}}\right)$ under varying iron limitation were of approximately the same magnitude as $\alpha^{c h l}$, so that $P_{\mathrm{m}}^{\mathrm{C}} / \alpha^{\mathrm{chl}} \theta_{\max }^{\mathrm{Fe}}$ remained approximately constant. In contrast, where $P_{\mathrm{m}}^{\mathrm{C}}$ increases as a result of abundant iron and/or $\mathrm{PO}_{4}$, the importance of iron dependencies on $\alpha^{\text {chl }}$ and $\theta_{\max }^{\mathrm{Fe}}$ also increase, since the term $P_{\mathrm{m}}^{\mathrm{C}} / \alpha^{\mathrm{chl}} \theta_{\max }^{\mathrm{Fe}}$ becomes relatively large. Temperature has a related effect on light limitation in the simulations, since at high temperature, rapid lightsaturated photosynthesis rates increase the demand for light, leading to a greater importance of iron-light colimitation in tropical waters. In contrast, the low inherent growth rates in cold waters of the Southern Ocean reduced the demand for photons, such that the impact of iron on photosynthetic efficiency was relatively unimportant.
Figure 14 illustrates the effect of this interaction between terms on the export production, with panel (a) showing the linear sum of the changes in export production expected by comparing each of the experiments $\operatorname{Var} \alpha / \theta$ and VarLiebig, and panel (b) showing the changes in export production actually simulated in experiment AllVar. The difference between these two panels reveals the impact of VarLiebig on the impact of the photosynthetic efficiency. In most of the world, the impact of iron on photosynthetic efficiency is muted by the effect on $P_{\mathrm{m}}^{\mathrm{C}}$. Only in parts of the Northern Hemisphere, where high seasonal abundances of iron drive all three terms to increase, does the amplitude of change in the AllVar model (panel b) exceed the linear sum (panel a). These clear predictions offer a target that iron enrichment experiments can test by deliberately isolating the effects of temperature, macronutrient limitation, and light.

The correlation and regression coefficients for the range of experiments (Table 2) showed little improvement when Var $\alpha$ was included, for which we offer an explanation here. Much of the conceptual basis for this paper is based on pulsed iron additions applied to bottle incubations or mesoscale patches, which reflect the response of a given species or community to changes in iron availability. However, observations of natural communities across gradients of iron availability in the Southern Ocean suggest that community-wide responses to long-term iron limitation may diverge from the more clearcut, short-term responses of iron-fertilization experiments on isolated assemblages. In particular, Hopkinson et al. (2007) showed that changes in $\alpha^{\text {chl }}$ between naturally iron-rich shelf and iron-poor open-ocean waters had no clear relationship to iron availability.

We propose that the long-term adjustment of ocean ecosystems to the available iron supply differs from the short-term response of biota to pulsed iron enrichments, 
in terms of $\alpha^{\text {chl }}$. The tendency for communities to become dominated by small plankton under iron-limitation, simply due to diffusion effects (Morel et al., 1991), will serendipitously increase $\alpha^{\mathrm{chl}}$, since small plankton have inherently more efficient photosynthetic machinery due to reduced "packaging effects" (Greene et al., 1991). Thus, we speculate that even though many phytoplankton (particularly diatoms) can increase their photosynthetic efficiencies given sufficient iron (e.g. Strzepek and Harrison, 2004), the phytoplankton that dominate iron-limited systems have inherently high photosynthetic efficiencies, so that the global distribution of iron is not strongly correlated with community $\alpha^{\text {chl }}$. The fact that our experiments show clear improvements in the simulations of global macronutrients and chlorophyll (Table 2) when both $P_{\mathrm{m}}^{\mathrm{C}}$ and $\theta$ vary (experiment $\operatorname{Var} \theta+$ Liebig), but not when $\alpha^{\text {chl }}$ is allowed to vary as well (experiment AllVar), would be consistent with a weak dependence of $\alpha^{\text {chl }}$ on iron across natural communities.

We hasten to emphasize that our results depend on the particular choice of parameters, such as the maximum growth rate, functional dependence of $\alpha^{\text {chl }}$ on $\mathrm{Def}_{\mathrm{Fe}}$, and iron half saturation coefficients, for which appropriate values are poorly constrained. Nonetheless, our results can be used to evaluate how particular combinations of parameter choices might give different results. For example, it would have been possible to use a larger $P_{\max }^{\mathrm{C}}$, balanced with smaller $\alpha_{\max }^{\mathrm{chl}}$ and $\theta_{\max }$, so as to maintain similar growth rates. As this would increase the term $P_{\mathrm{m}}^{\mathrm{C}} / \alpha^{\mathrm{chl}} \theta_{\max }^{\mathrm{Fe}}$, they would act to increase the global severity of light limitation, making the impact of iron limitation on photosynthetic efficiency somewhat more important than in the simulations we show here. On the other hand, if one were to decrease $P_{\max }^{\mathrm{C}}$ and increase $\alpha_{\max }^{\mathrm{chl}}$ and $\theta_{\max }$, the result would be to make the impact of iron limitation on photosynthetic efficiency even less important than in the simulations we show here.The fact that all of these parameters are likely to vary with ecosystem composition, rather than adhering to well-behaved global constants, further limits these results to the illustration of principles.

In closing, our results suggest that models which do not parameterize the effects of iron availability on photosynthetic efficiency are not missing much in terms of simulating global-scale biogeochemistry, due to the dominant impact of iron availability on the light-saturated photosynthesis rate. However, they are likely to impact more subtle features of global simulations, such as the vertical distribution of phytoplankton within the water column, and the seasonal cycle of primary production, particularly spring blooms in the North Atlantic.

Acknowledgements. We thank Jorge Sarmiento, Charles Stock, Whit Anderson and Patrick Schultz for helpful discussions, Stephanie Henson for providing the SeaWiFS climatology, Richard Slater for computer assistance, and Christopher Measures for sharing the iron concentration data. Adrian Marchetti, Brian Hopkinson and Julie Granger commented on an early version of the draft. Alex Tagliabue and Olivier Aumont provided detailed and constructive reviews.

Edited by: L. Bopp

\section{References}

Agawin, N. S. R., Duarte, C. M., and Agusti, S.: Nutrient and temperature control of the contribution of picoplankton to phytoplankton biomass and production, Limnol. Oceanogr., 45, 591600, 2000.

Anderson, L. A : On the hydrogen and oxygen content of marin phytoplankton. Deep Sea Res. Pt. I, 42, 1675-1680, 1995.

Aumont, O. and Bopp, L.: Globalizing results from in-situ iron fertilization studies, Global Biogeochem. Cycles, 20, GB2017, doi:10.1029/2005GB002591, 2006.

Aumont, O., Maier-Reimer, E., Blain, S., and Monfray, P.: An ecosystem model of the global ocean including $\mathrm{Fe}, \mathrm{Si}$, $\mathrm{P}$ colimitations, Global Biogeochem. Cycles, 17(2), 1060, doi:10.1029/2001GB001745, 2003.

Aumont, O., Bopp, L., and Schulz, M.: What does temporal variability in aeolian dust deposition contribute to sea-surface iron and chlorophyll distributions?, Geophys. Res. Lett., 35, L07607, doi:10.1029/2007GL031131, 2008.

Barbeau, K., Rue, E. L., Bruland, K. W., and Butler, A.: Photochemical cycling of iron in the surface ocean mediated by microbial iron(III)-binding ligands, Nature, 413, 409-413, 2001.

Barbeau, K., Rue, E. L., Trick. C. L., Bruland, K. W., and Butler, A.: Photochemical reactivity of siderophores produced by marine heterotrophic bacteria and cyanobacteria based on $\mathrm{Fe}(\mathrm{III})$, Limnol Oceanogr., 48, 1069-1078, 2003.

Behrenfeld, M. J. and Falkowski, P. G.: Photosynthetic rates derived from satellite-based chlorophyll concentration, Limnol. Oceanogr., 42, 1-20, 1997.

Bopp, L., Aumont, O., Cadule, P., Alvain, S., and Gehlen, M.: Response of diatoms distribution to global warming and potential implications: A global model study, Geophys. Res. Lett., 32, L19606, doi:10.1029/2005GL023653, 2005.

Boyd, P. W., Jickells, T., Law, C. S., et al.: Mesoscale iron enrichment experiments 1993-2005: Synthesis and future directions, Science, 315, 612-617, 2007.

Carr, M.-E.: Estimation of potential productivity in Eastern Boundary Currents using remote sensing, Deep Sea Res., Part II, 49, 59-80, 2002.

Davey, M. and Geider, R. J.: Impact of iron limitation on the photosynthetic apparatus of the diatom Chaetoceros muelleri (bacillariophyceae), J. Phycol., 37, 987-1000, 2001.

Doney, S. C., Lindsay, K., Fung, I., and John, J.: Natural variability in a stable, 1000- Yr global coupled carbon-climate model simulation, J. Climate, 19, 3033-3054, 2006.

Dugdale, R. C. and Goering, J. J.: Uptake of new and regenerated forms of nitrogen in primary productivity, Limnol. Oceanogr., 12, 196-206, 1967.

Dunne, J. P., Armstrong, R. A., Gnanadesikan, A., and Sarmiento, J. L.: Empirical and mechanistic models of the particle export ratio, Global Biogeochem. Cycles, 19, GB4026, doi:10.1029/2004GB002390, 2005.

Dunne, J. P., Sarmiento, J. L., and Gnanadesikan, A.: A synthesis of global particle export from the surface ocean and cycling through 
the ocean interior and on the seafloor, Global Biogeochem. Cycles, 21, GB4006, doi:10.1029/2006GB002907, 2007.

Dusenberry, J., Olson, R. J., and Chisholm, S. W.: Photoacclimation kinetics of single-celled fluorescence in laboratory and field populations of Prochlorococcus, Deep Sea Res. I, 48, 1443-1458, 2001.

Dutkiewicz, S., Follows, M. J., and Parekh, P.: Interactions of the iron and phosphorus cycles: A three-dimensional model study, Global Biogeochem. Cycles, 19, GB1021, doi:10.1029/2004GB002342, 2005.

Elrod, V. A., Berelson, W. M., Coale, K. H., and Johnson, K. S.: The flux of iron from continental shelf sediments: A missing source for global budgets, Geophys. Res. Lett., 31, L12307, doi:10.1029/2004GL020216, 2004.

Eppley, R. W.: Temperature and phytoplankton growth in the sea, Fish. Bull., 70, 1063-1085, 1972.

Fasham, M. J. R., Flynn, K. J., Pondaven, P., Anderson, T. R., and Boyd, P. W.: Development of a robust marine ecosystem model to predict the role of iron in biogeochemical cycles: A comparison of results for iron-replete and iron-limiter areas, and the SOIREE iron-enrichment experiment, Deep Sea Res. I, 53, 333 366, 2006

Frennette, J. J., Demers, S., Legendre, L., and Dodson, J.: Lack of agreement among models for estimating the photosynthetic parameters, Limnol. Oceanogr., 38, 679-687, 1993.

Geider, R. J., MacIntyre, H. L., and Kana, T. M.: Dynamic model of phytoplankton growth and acclimation: Response of the balanced growth rate and chlorophyll a to carbon ratio to light, nutrient limitation and temperature, Mar. Ecol. Prog. Ser., 148, 187201, 1997.

Gent, P. J. and McWilliams, J. C.: Isopycnal mixing in ocean circulation models, J. Phys. Oceanogr., 20, 150-155, 1990.

Ginoux, P., Prospero, J. M., Torres, O., and Chin, M.: Longterm simulation of global dust distribution with the GOCART model: correlation with North Atlantic Oscillation, Environ. Model. Softw., 19, 113-128, 2004.

Gnanadesikan, A., Dixon, K. W., Griffies, S. M., et al.: GFDL's CM2 Global Coupled Climate Models- Part 2: The baseline ocean simulation, J. Climate, 19, 675-697, 2006.

Gnanadesikan, A., Dunne, J. P., Key, R. M., Matsumoto, K., Sarmiento, J. L., Slater, R. D., and Swathi, P. S.: Oceanic ventilation and biogeochemical cycling: Understanding the physical mechanisms that produce realistic distributions of tracers and productivity, Global Biogeochem. Cycles, 18(4), GB4010, doi:10.1029/2003GB002097, 2004.

Gnanadesikan, A., Slater, R. D., Gruber, N., and Sarmiento, J. L.: Oceanic vertical exchange and new production, a comparison between models and data, Deep Sea Res. Pt. II, 49, 363-401, 2002.

Gnanadesikan, A., Griffies, S. M., and Samuels, B. L.: Effects in a climate model of slope tapering on neutral physics schemes, Ocean Modelling, 16, 1-16, doi:10.1016/j.ocemod.2006.06.004, 2007.

Granger, J. and Price, N. M.: The importance of siderophores in the iron nutrition of heterotrophic marine bacteria, Limnol. Oceanogr., 44, 541-555, 1999.

Greene, R. M., Geider, R. J., and Falkowski, P. G.: Effect of iron limitation on photosynthesis in a marine diatom, Limnol. Oceanogr., 36, 1772-1782, 1991.

Griffies, S. M., Hallberg, R. W., Pirani, A., et al.: Coordinated
Ocean-ice Reference Experiments (COREs), Ocean Model., 26, 1-46, 2009.

Griffies, S. M., Gnanadesikan, A., Dixon, K. W., Dunne, J. P., Gerdes, R., Harrison, M. J., Rosati, A., Russell, J. L., Samuels, B. L., Spelman, M. J., Winton, M., and Zhang, R.: Formulation of an ocean model for global climate simulations, Ocean Sci., 1, 45-79, 2005, http://www.ocean-sci.net/1/45/2005/.

Hiscock, M. R., Lance, V. P., Apprill, A., Bidigare, R .R., Johnson, Z. I., Mitchell, B. G., Smith, W. O., and Barber, R. T.: Photosynthetic maximum quantum yield increases are an essential component of the Southern Ocean phytoplankton response to iron, Proc. Natl. Acad. Sci., 105, 4775-4780, 2008.

Honeyman, B., Balistrieri, L., and Murray, J.: Oceanic trace metal scavenging and the importance of particle concentration, Deep Sea Res., Pt I, 35, 227-246, 1988.

Hopkinson, B. M., Mitchell, B. G., Reynolds, R. A., Wang, H., Selph, K. E., Measures, C. I., Hewes, C. D., Holm-Hansen, O., and Barbeau, K. A.: Iron limitation across chlorophyll gradients in the southern Drake Passage: Phytoplankton responses to iron addition and photosynthetic indicators of iron stress, Limnol. Oceanogr., 52(6), 2540-2554, 2007.

Hutchins, D. A., DiTullio, G. R., Zhang, Y., and Bruland, K. W.: An iron limitation mosaic in the California upwelling regime, Limnol. Oceanogr., 43, 1037-1054, 1998.

Johnson, K., Gordon, R. M., and Coale, K. H.: What controls dissolved iron concentrations in the world ocean?, Mar. Chem., 57 137-161, 1997.

Klausmeier, C. A., Litchman, E., Daufresne, T., and Levin, S. A.: Optimal nitrogen-to-phosphorus stoichiometry of phytoplankton, Nature, 429, 171-174, 2004.

Kriest, I. and Oschlies, A.: On the treatment of particulate organic matter sinking in large-scale models of marine biogeochemical cycles, Biogeosciences, 5, 55-72, 2008, http://www.biogeosciences.net/5/55/2008/.

Lam, P. J., Bishop, J. K. B., Henning, C. C., Marcus, M. A., Waychunas, G. A., and Fung, I. Y.: Wintertime phytoplankton bloom in the subarctic Pacific supported by continental margin iron, Global Biogeochem. Cycles, 20, GB1006, doi:10.1029/2005GB002557, 2006.

Large, W., McWilliams, J. C., and Doney, S. C.: Oceanic vertical mixing: A review and a model with a nonlocal boundary mixing parameterization, Rev. Geophys., 32, 363-403, 1994.

Mahowald, N. M., Baker, A. R., Bergametti, G., Brooks, N., Duce, R. A., Jickells, T. D., Kubilay, N., Prospero, J. M., and Tegen, I.: Atmospheric global dust cycle and iron inputs to the ocean, Global Biogeochem. Cycles, 19, GB4025, doi:10.1029/2004GB002402, 2005.

Maldonado, M. T., Boyd, P. W., Harrison, P. J., and Price, N. M.: Co-limitation of phytoplankton growth by light and $\mathrm{Fe}$ during winter in the NE subarctic Pacific Ocean, Deep-Sea Res. II, 46, 2475-2485, 1999.

Manizza, M., Le Quere, C., Watson, A. J., and Buitenhuis, E. T.: Bio-optical feedbacks among phytoplankton, upper ocean physics and sea-ice in a global coupled model, Geophys. Res. Lett., 32, L05603, doi:10.1029/2004GL020778., 2005.

Marchetti, A., Juneau, P., Whitney, F. A., Wong, C. S., and Harrison, P. J.: Phytoplankton processes during a mesoscale iron enrichment in the NE subarctic Pacific: Part III - primary productivity, 
Deep Sea Res. II, 53, 2131-2151, 2006a.

Marchetti, A., Maldonado, M. T., Lane, E. S., and Harrison, P. J.: Iron requirements of the pennate diatom Pseudo-nitzschia: Comparison of oceanic (high-nitrate, low-chlorophyll waters) and coastal species, Limnol. Oceanogr., 51, 2092-2101, 2006b.

Marchetti, A. and Harrison, P. J.: Coupled changes in the cell morphology and the elemental (C,N, and $\mathrm{Si}$ ) composition of the pennate diatom Pseudo-nitzaschia due to iron deficiency, Limnol. Oceanogr., 52(5), 2270-2284, 2007.

Marchetti, A., Parker, M. S., Moccia, L. P., Lin, E. O., Arrieta, A. L., Ribalet, F., Murphy, M. E. P., Maldonado, M. T., and Armbrust, E. V.: Ferritin is used for iron storage in bloom-forming marine pennate diatoms, Nature, 457, 467-470, 2009.

Marra, J., Ho, C., and Trees, C. C.: An alternative algorithm for the calculation of primary productivity from remote sensing data, LDEO Tech. Rep. LDEO-2003-1, Lamont Doherty Earth Obs., Palisades, NY, 2003.

Measures, C. I., Landing, W. M., Brown, M. T., and Buck, C. S.: High resolution $\mathrm{Al}$ and $\mathrm{Fe}$ data from the Atlantic Ocean CLIVAR-CO2 Repeat Hydrography A16N transect: Extensive linkages between atmospheric dust and upper ocean geochemistry, Global Biogeochem. Cycles, 22, GB1005, doi:10:1029/2007GB003042, 2008.

Moore, J. K., Doney, S. C., Kleypas, J. C., Glover, D. M., and Fung, I. Y.: An intermediate complexity marine ecosystem model for the global domain, Deep-Sea Res. II, 49, 403-462, 2002.

Moore, J. K., Doney, S. C., and Lindsay, K.: Upper ocean ecosystem dynamics and iron cycling in a global 3-D model, Global Biogeochem. Cycles, 18, GB4028, doi:10.1029/2004GB002220, 2004.

Moore, J. K. and Braucher, O.: Sedimentary and mineral dust sources of dissolved iron to the world ocean, Biogeosciences, 5, 631-656, 2008, http://www.biogeosciences.net/5/631/2008/.

Moore, J. K. and Doney, S. C.: Iron availability limits the ocean nitrogen inventory stabilizing feedbacks between marine denitrification and nitrogen fixation, Global Biogeochem. Cycles, 21, GB2001, doi:10.1029/2006GB002762, 2007.

Morel, F. M. M., Hudson, R. J. M., and Price, N. M.: Limitation of productivity by trace metals in the sea, Limnol. Oceanogr., 36, 1742-1755, 1991.

Najjar, R. G. and Orr, J. C.: Biotic HOWTO, Internal OCMIP Report, LSCE/CEA Saclay, Gif-sur-Yvette, France, 15 pp., 1999.

Parekh, P., Follows, M. J., and Boyle, E. A.: Decoupling of iron and phosphate in the global ocean, Global Biogeochem. Cycles, 19, GB2020, doi:10.1029/2004GB002280, 2005.

Price, N. M., Andersen, L. F., and Morel, F. M. M.: Iron and nitrogen limitation of equatorial Pacific plankton, Deep Sea Res. I, 38, 1361-1378, 1991.

Raven, J.: Predictions of Mn and Fe use efficiencies of phototropic growth as a function of light availability for growth and of $\mathrm{C}$ assimilation pathway, New Phytol., 116, 1-18, 1990.
Rue, E. L. and Bruland, K. W.: Complexation of iron(III) by natural organic ligands in the Central North Pacific as determined by a new competitive ligand equilibration/adsorptive cathodic stripping voltametric method, Mar. Chem., 50, 117-138, 1995.

Schmittner, A., Galbraith, E. D., Hostetler, S. W., Pederson, T. F., and Zhang R.: Large fluctuations of dissolved oxygen in the Indian and Pacific oceans during Dansgaard- Oeschger oscillations caused by variations of North Atlantic Deep Water subduction, Paleoceanography, 22, PA3207, doi:10.1029/2006PA001384, 2007.

Siegel, D. A., Mariotorena, S., Nelson, N. B., and Behrenfeld, M. J.: Independence and interdependencies among global ocean color properties: Reassessing the bio-optical assumption, J. Geophys. Res., 110, C07011, doi:10.1029/2004JC002527, 2005.

Simmons, H. L., Jayne, S. R., St. Laurent, L. C., and Weaver, A. J.: Tidally-driven mixing in a numerical model of the ocean general circulation, Ocean Model., 6, 245-263, 2004.

Strzepek, R. F. and Harrison, P. J.: Photosynthetic architecture differs in coastal and oceanic diatoms, Nature, 431, 689-692, 2004.

Sunda, W. G. and Huntsman, S. A.: Interrelated influence of iron, light, and cell size on marine phytoplankton growth, Nature, 390, 389-392, 1997.

Tagliabue, A. and Arrigo, K. R.: Iron in the Ross Sea: Processes governing the supply of iron to phytoplankton in stratified seas, J. Geophys. Res., 111, C06019, doi:10.1029/2005JC003363, 2006.

Tagliabue, A., Bopp, L., Aumont, O., and Arrigo, K. R.: Influence of light and temperature on the marine iron cycle: from theoretical to global modeling, Global Biogeochem. Cycles, 23, GB2017, doi:10.1029/2008GB003214, 2009.

Timmermans, K. R., van der Wagt, B., Veldhuis, M. J. W., Maatman, A., and De Baar, H. J. W.: Physiological responses of three species of marine pico-plankton to ammonium, phosphate, iron and light limitation, J. Sea Res., 53, 109-120, 2005.

Tortell, P. D., Maldonado, M. T., Granger, J., and Price, N. M.: Marine bacteria and biogeochemical cycling of iron in the oceans, FEMS Microbio. Ecol., 29, 1-11, 1999.

Trick, C. G., Andersen, R. J., Price, N. M., Gillam, A., and Harrison, P. J.: Examination of hydroxamate-siderophore production by neritic eukaryotic marine phytoplankton, Mar. Biol., 75, 9-17, 1983.

Tyrrell, T.: The relative influences of nitrogen and phosphorus on oceanic primary production, Nature, 400, 525-531, 1999.

Weber, L., Volker, C., Schartau, M., and Wolf-Gladrow, D.: Modeling the biogeochemistry and speciation of iron at the Bermuda Atlantic Time Series site, Global Biogeochem. Cycles, 19, GB1019, doi:10.1029/2004GB002340, 2005.

Wu, J., Boyle, E., Sunda, W., and Wen, L.-S.: Soluble and colloidal iron in the oligotrophic North Atlantic and North Pacific, Science, 293, 847-849, 2001. 